\title{
Understanding the Relationship between China's Eco-Environmental Quality and Urbanization Using Multisource Remote Sensing Data
}

\author{
Dong $X u^{1,2,3,4,+}{ }^{D}$, Jie Cheng ${ }^{2,3}{ }^{\mathbb{D}}$, Shen $X u^{5}$, Jing Geng ${ }^{6}$, Feng Yang ${ }^{7}$, He Fang ${ }^{1, *}$, Jinfeng $X u^{4}$, Sheng Wang ${ }^{4}$, \\ Yubai Wang ${ }^{4}$, Jincai Huang ${ }^{8}\left(\mathbb{D}\right.$, Rui Zhang ${ }^{9}$, Manqing Liu ${ }^{2,3}$ and Haixing Li $^{4,+}+(\mathbb{D}$
}

check for

updates

Citation: Xu, D.; Cheng, J.; Xu, S.; Geng, J.; Yang, F.; Fang, H.; Xu, J.; Wang, S.; Wang, Y.; Huang, J.; et al. Understanding the Relationship between China's Eco-Environmental Quality and Urbanization Using Multisource Remote Sensing Data. Remote Sens. 2022, 14, 198. https:// doi.org/10.3390/rs14010198

Academic Editor: Ronald C. Estoque

Received: 31 October 2021

Accepted: 23 December 2021

Published: 2 January 2022

Publisher's Note: MDPI stays neutral with regard to jurisdictional claims in published maps and institutional affiliations.

Copyright: (c) 2022 by the authors. Licensee MDPI, Basel, Switzerland. This article is an open access article distributed under the terms and conditions of the Creative Commons Attribution (CC BY) license (https:// creativecommons.org/licenses/by/ $4.0 /)$.
1 Zhejiang Climate Center, Hangzhou 310052, China

2 State Key Laboratory of Remote Sensing Science, Faculty of Geographical Science, Beijing Normal University, Beijing 100875, China; xd@mail.bnu.edu.cn (D.X.); Jie_Cheng@bnu.edu.cn (J.C.); 202131051048@mail.bnu.edu.cn (M.L.)

3 Faculty of Geographical Science, Institute of Remote Sensing Science and Engineering, Beijing Normal University, Beijing 100875, China

4 College of Geomatics Science and Technology, Nanjing Tech University, Nanjing 211816, China; 202061223009@njtech.edu.cn (J.X.); 202061223008@njtech.edu.cn (S.W.); 202061123001@njtech.edu.cn (Y.W.); lihaixing@njtech.edu.cn (H.L.)

5 School of Psychological and Cognitive Sciences, Peking University, Beijing 100871, China; xs-psych@stu.pku.edu.cn

6 Academician Workstation of Zhai Mingguo, University of Sanya, Sanya 572000, China; jinggeng@sanyau.edu.cn

7 School of Environmental Science and Engineering, Southern University of Science and Technology, Shenzhen 518055, China; yftaurus@mail.bnu.edu.cn

8 Shenzhen Key Laboratory of Spatial Smart Sensing and Service, Shenzhen University, Shenzhen 518060, China; huangjincaiszu@szu.edu.cn

9 School of Geography and Information Engineering, China University of Geosciences, Wuhan 430074, China; 1202010859@cug.edu.cn

* Correspondence: fanghe_doc@163.com

+ These authors contributed equally to this work.

Abstract: The rapid development of urbanization and population growth in China has posed a major threat to the green sustainable development of the ecological environment. However, the impact of urbanization on the eco-environmental quality (EEQ) in China remains to be developed. Understanding their interactive coupling mechanism is of great significance to achieve the urban sustainable development goals. By using multi-source remote sensing data and the coupling coordination degree model (CCDM), we intended to answer the question "What are the temporal and spatial characteristics of urbanization and EEQ in China on the pixel scale during 2000-2013, and what is the coupling mechanism between the urbanization and the EEQ?". To answer these questions, we explored the coupling mechanism between urbanization and the EEQ in China with a combined mathematical and graphics model. The results show that the urbanization and the coupling coordination degree (CCD) of the whole region continually increased from 2000 to 2013, especially in the three major urban agglomerations, with a spatial distribution pattern that was "high in the east and low in the west". Most importantly, from 2000 to 2013, the CCD type of cities in China gradually evolved from uncoordinated cities to coordinated cities. Additionally, the decisive factor affecting the CCD from 2000 to 2013 was the development of urbanization, and the degree at which urbanization had an impact on CCD was about 8.4 times larger than that of the EEQ. At the same time, the rapid urbanization that has occurred in some areas has led to a significant decline in the EEQ, thus indicating that China needs to increase its protection of the ecological environment while pursuing social and economic development in the future. This study makes up for the deficiencies in the existing literature and investigates the long-term coupling of the EEQ and urbanization in China, thereby providing a new research perspective for the sustainable development of China and even the world in the future. 
Keywords: M-RSEQI; DMSP; entropy method; coupling coordination degree model; remote sensing data; urbanization

\section{Introduction}

Since the beginning of the current century, China has experienced a period of urbanization that is unprecedented in human history. During this period, the speed of urbanization development in China was approximately three times larger than the world average during the same period [1,2]. Rapid urbanization has led to serious environmental problems, such as the depletion of natural resources and the destruction of ecosystem services [3]. Severe ecological and environmental problems restrict China from having a healthy economy and societal development and threatens regional sustainable development [4-6]. In terms of this increasingly severe eco-environmental situation, it is increasingly important to conduct effective scientific research on monitoring the coupling of China's eco-environment quality (EEQ) and urbanization in order to ensure the realization of "China's 2030 sustainable development goals" [7].

Currently, research on EEQ assessment has made great progress [8]. In 1979, David J. Rapport and Tony Friend firstly proposed the "pressure-state-response" (PSR) framework [9], which reflects the relationship among natural, social, and economic factors from the perspective of environmental protection and economic development, and this framework has been widely used in EEQ assessment studies [8]. Based on the PSR framework, the European Environment Agency (EEA) [10], the United States Environmental Protection Agency (USEPA) [11], and the Council for Sustainable Development (CSD) [12] have all proposed improved models for EEQ assessment in different regions. With the emergence of the concept of sustainable development, research methods have gradually developed EEQ assessment models that are based on sustainable development, and these models include ecological footprint (EF) [13] and the environmental sustainability index (ESI) [14]. Through summarizing existing studies, we found that previous research had two shortcomings. First, the environmental assessments mainly focused on the assessment of ecological risks, ecological effects, and ecological fragility and lacked a comprehensive assessment of the overall EEQ of the region. Secondly, most of the studies relied heavily on panel statistical data, which led to uncertainty in the study results due to the diversity of the sources of panel statistical data. In terms of urbanization assessment, current research methods are mainly based on panel statistical data that are implemented around different assessment systems, similar to EEQ assessments [15-18]. Therefore, studies that evaluate urbanization also have the two abovementioned shortcomings.

The rapid development of remote sensing sensors and the open access of massive remote sensing data have greatly promoted Earth observation research on the regional scale $[19,20]$. In 2020, Estoque (2020) elaborated on the status, challenges, and opportunities of the remote sensing (RS) monitoring of the Sustainable Development Goals and pointed out that remote sensing technology is an important environmental monitoring tool that can help fill the gaps in environmental data [21]. For example, the RSEI model proposed by $\mathrm{Xu}$ [22] in 2013 has been widely applied to assess the EEQ in different regions [23-25]. However, these studies often overlook an important principle, i.e., the definition of EEQ should be evaluated on the basis of the entire territory of China. For example, the EEQ of the Qinghai-Tibet Plateau calculated by the RSEI index is not comparable with that of the Loess Plateau. Secondly, many studies have found that the application of the RSEI index on a large scale has larger uncertainty, especially in regions with abundant land cover types, which creates a gap in the current research on remotely sensed EEQ assessments in China [26]. Remote sensing technology has also made great progress in the quantitative assessment of urbanization. Currently, urbanization monitoring methods using remote sensing are generally divided into two categories: multispectral remote sensing and nighttime light remote sensing. For example, Li [27] proposed an urban boundary extraction algorithm 
(GA-UCAT) that was based on the normalized building index (NDBI). Zhang [28] analyzed the urbanization development of India, China, Japan, and the United States from 1992 to 2000 based on DMSP nighttime light data. However, the advantages of nighttime light data in characterizing the level of urbanization have been verified [29-31].

The theories on the interaction and coupling of the EEQ and urbanization mainly include the environmental Kuznets curve (EKC) [32,33], the planetary boundaries theory [34,35], the tele-coupling theory [36,37], the footprint family theory [38,39], and the urban metabolism theory [40,41]. Related models mainly include the STIRPAT model [42], the coupling coordination degree model (CCDM) [43], and the multiagent model [44]. Among them, CCDM is the most widely used [45]. Zhao [46] studied the coupling of the EEQ and urbanization in the Yangtze River Basin from 1980 to 2013 through the EKC and dynamic CCDM and found that the EEQ and urbanization conformed to the S-shaped curve of the coupling and coordination relationship. Li [47] used the CCDM to study the coupling relationship between the EEQ and urbanization in Lianyungang and found that the coupling coordination degree (CCD) presented an inverted U-shaped curve, and Wang et al. also reached a similar conclusion [48]. Some scholars used the double exponential model and the CCDM to verify the nonlinear relationship between the EEQ and urbanization [49].

Under the context that the sustainable development goals (SDGs) are becoming a global strategic development goal, research on the coupling of the regional EEQ and urbanization has gradually become a global hot topic [45]. By reviewing previous studies, their shortcomings were summarized. Firstly, most existing studies were based on statistical data. The diverse data sources and the low temporal and spatial resolution of statistical data have led to great uncertainty in the research results. Since the sources of statistical data in China can be divided into the national and provincial levels, the same indicators published by different agencies, which contain huge human factors, are very different. Another uncertainty of statistical data comes from the timeliness. For example, with the change of the definition of an indicator, the indicator may stop updating in the future or may be replaced by another indicator, which will cause great uncertainty to the statistical data. On the other hand, studies based on statistical data may also result in low spatial resolution characteristics. Therefore, these research results usually cannot show the surface details on the pixel scale. Secondly, there is currently a lack of studies on the long-term continuous coupling of the EEQ and urbanization in China. To address these issues, this study explored the coupling mechanism between the EEQ and urbanization in China from 2000 to 2013 using the CCDM and multisource remote sensing data.

This study counterbalances the shortcomings of existing research and fills gaps in the research on the coupling mechanism between the EEQ and urbanization. Additionally, this study provides a new perspective for research on urban sustainable development in China, which can also be extended to the global research.

\section{Study Area and Data}

\subsection{Study Area}

China is located in eastern Asia, with the terrain gradually rising in elevation from east to west and a rich ecosystem. There are three forest areas in northeastern and southern China, with the Inner Mongolia Plateau constituting China's largest grassland resource and representing the largest ecosystem type in China (Figure 1). Lakes of various sizes, most of which are distributed on the Qinghai-Tibet Plateau constitute China's complex wetland ecosystem. The Qinghai-Tibet Plateau is the largest ice accumulation area in the world after the North and South poles, and this region is called the "Asian Water Tower" [50]. Therefore, the EEQ of China plays an important role in the stability of China's ecosystem. 


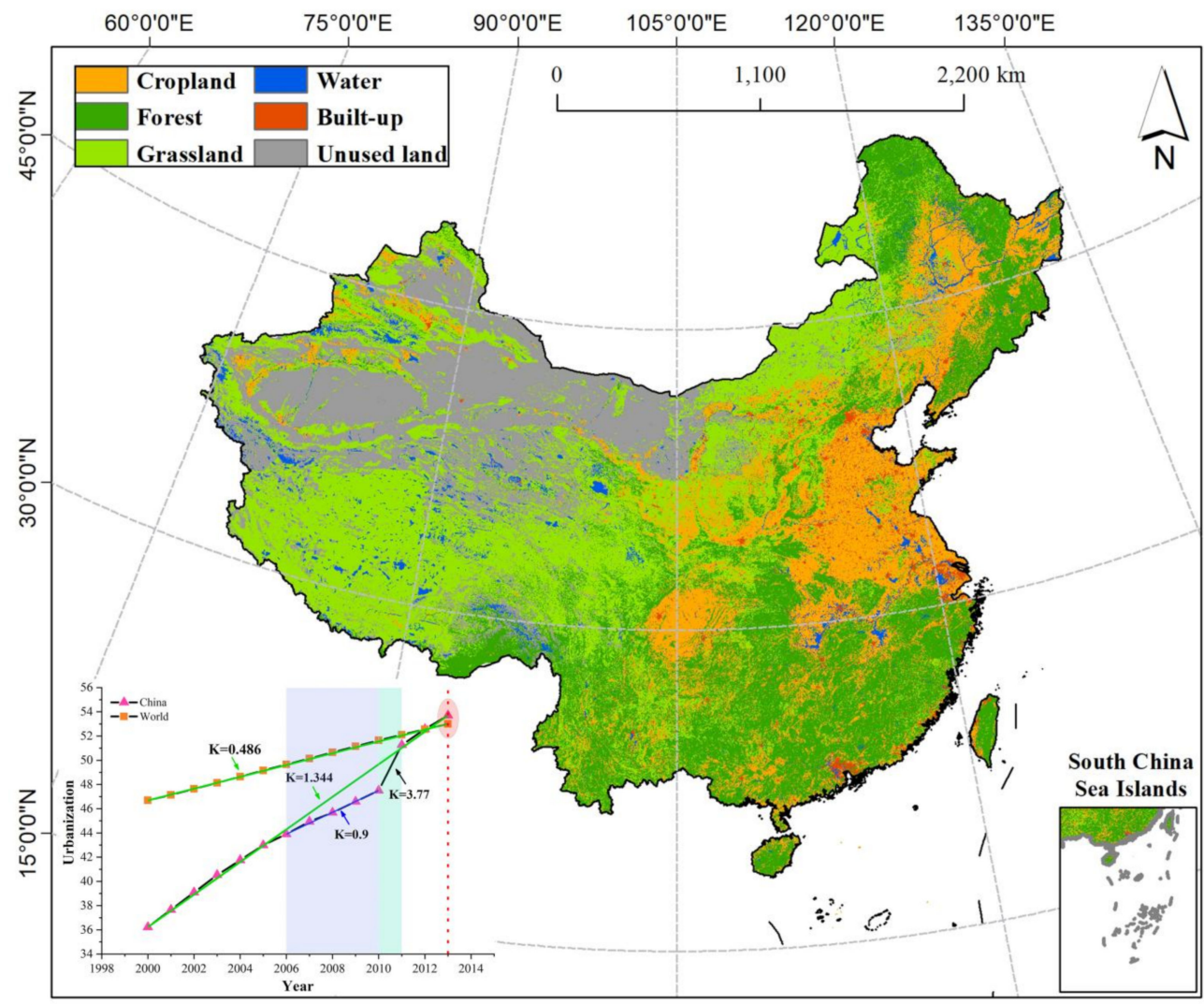

Figure 1. Land use map (MCD12Q1) of China in 2013 and line chart of the urbanization rates in China and the world from 2000 to 2013 (bottom left). The light blue shaded area represents the slow growth stage of the urbanization rate, while the light green area represents the rapid growth stage.

Since the 21st century, China has experienced the largest and fastest urbanization process in its history [51]. The urbanization rate increased from $36.22 \%$ in 2000 to $53.7 \%$ in 2013 , with an annual average growth rate of 1.344 , which is much higher than the world average of 0.486. As shown in Figure 1, the urbanization process in China from 2000 to 2013 experienced slow and rapid growth. From 2006 to 2010, the average growth rate of China's urbanization, with a rate of 0.9 , was higher than the global growth rate of 0.498 during the same period, which was much lower than the annual average growth rate over the 14-year period. From 2010 to 2011, China's urbanization rate increased rapidly, and the growth rate reached 3.77. China's urbanization rate exceeded the world average for the first time in 2013, which is the end of the time series of this study.

\subsection{Data}

Multisource remote sensing data were used in this study, including precipitation (PRE), temperature (TEMP), net primary productivity (NPP), vegetation coverage (FVC), digital elevation model (DEM), land use and land cover change (LULC), population density (POP), potential evapotranspiration (PET), and DMSP (Defense Meteorological Satellite Program) nighttime light data. The data used in this study are detailed in Table 1. 
Table 1. Detailed description of the data.

\begin{tabular}{|c|c|c|c|c|}
\hline $\begin{array}{l}\text { Data } \\
\text { Name }\end{array}$ & Format & Spatial Resolution & Time Resolution & Source \\
\hline 2019QZKK0603-zgyjsl [52] & NETCDF & $1000 \mathrm{~m}$ & Monthly & NTPDC $^{a}$ \\
\hline 2019QZKK0603-zgypjw [52] & NETCDF & $1000 \mathrm{~m}$ & Monthly & NTPDC $^{a}$ \\
\hline MOD17A3 & HDF & $1000 \mathrm{~m}$ & Monthly & NASA $^{\mathrm{b}}$ \\
\hline MOD13A3 & HDF & $250 \mathrm{~m}$ & Monthly & NASA $^{b}$ \\
\hline SRTM DEM & TIFF & $250 \mathrm{~m}$ & - & USGS $^{\mathrm{c}}$ \\
\hline MCD12Q1 & $\mathrm{HDF}$ & $1000 \mathrm{~m}$ & Seasonal & NASA $^{b}$ \\
\hline Landscan POP & TIFF & $1000 \mathrm{~m}$ & Annual & ORNL d \\
\hline MOD16A3 & HDF & $1000 \mathrm{~m}$ & Monthly & NASA $^{b}$ \\
\hline LUCC2000 & TIFF & $1000 \mathrm{~m}$ & Annual & CAS $^{\mathrm{e}}$ \\
\hline DMSP nighttime light & TIFF & $1000 \mathrm{~m}$ & Annual & NOAA $^{\mathrm{f}}$ \\
\hline Anthropogenic heat flux (AHF) & TIFF & $1000 \mathrm{~m}$ & Annual & Article [53] \\
\hline
\end{tabular}

${ }^{a}$ NTPDC: National Tibetan Plateau Data Center. ${ }^{b}$ NASA: National Aeronautics and Space Administration. ${ }^{\mathrm{c}}$ USGS: United States Geological Survey. ${ }^{\mathrm{d}}$ ORNL: Oak Ridge National Laboratory. ${ }^{\mathrm{e}}$ CAS: Chinese Academy of Sciences. ${ }^{\mathrm{f}}$ NOAA: National Oceanic and Atmospheric Administration.

\section{Methods}

The methods that were used in this study are divided into three parts: (1) the production of the Multisource Remote Sensing EEQ Index (M-RSEQI) (Section 3.1), (2) the processing of the quantitative calculation of urbanization (Section 3.2), and (3) the evaluation of the coupling processes between the M-RSEQI and urbanization (Section 3.3). The flowchart for this article is shown in Figure 2 and includes two parts: the flowchart of study methods (Figure 2a) and an example for 2000 (Figure 2b). The main process for Figure 2a is as follows: First, the annual mean value of eight indicators representing the EEQ was calculated and standardized, and then the dimension reduction of the eight indicators was carried out to calculate the M-RSEQI. Secondly, the DMSP nighttime light data were corrected and standardized. Finally, the processed DMSP nighttime light data and M-RSEQI were input into the CCDM to calculate the CCD.

\section{1. $M-R S E Q I$}

This study followed the principles for the selection of assessment indicators proposed by the China National Environmental Monitoring Centre [54], namely comprehensive principles, representative principles, scientific principles, comparability principles, and operability principles. Eight indicators were selected, as shown in Table 1.

To eliminate the influence of different index dimensions on the results, dimensionless treatment was needed for all of the indexes. The range standardization method was used to standardize the eight indicators that were used in this research. The selected indicators were divided into positive and negative indicators. Positive indicators included PRE, NPP, NDVI, DEM, and LUCC, which promoted the EEQ, while the negative indicators had negative effects on the EEQ, and included TEMP, POP, and PET. The standardized equations are as follows:

$$
\begin{aligned}
& \text { Positive indicator : } \\
r_{s}^{+}= & \left(I_{j}-I_{\min }\right) /\left(I_{\max }-I_{\min }\right) \\
& \text { Negative indicator : } \\
r_{s}^{-}= & \left(I_{\max }-I_{j}\right) /\left(I_{\max }-I_{\min }\right)
\end{aligned}
$$

where $r_{\mathrm{s}}{ }^{+}$is the standardized value of the $j$ th indicator, $I_{j}$ is the original value of the $j$ th indicator, and $I_{\min }$ and $I_{\max }$ are the minimum and maximum values of the $j$ th indicator. 


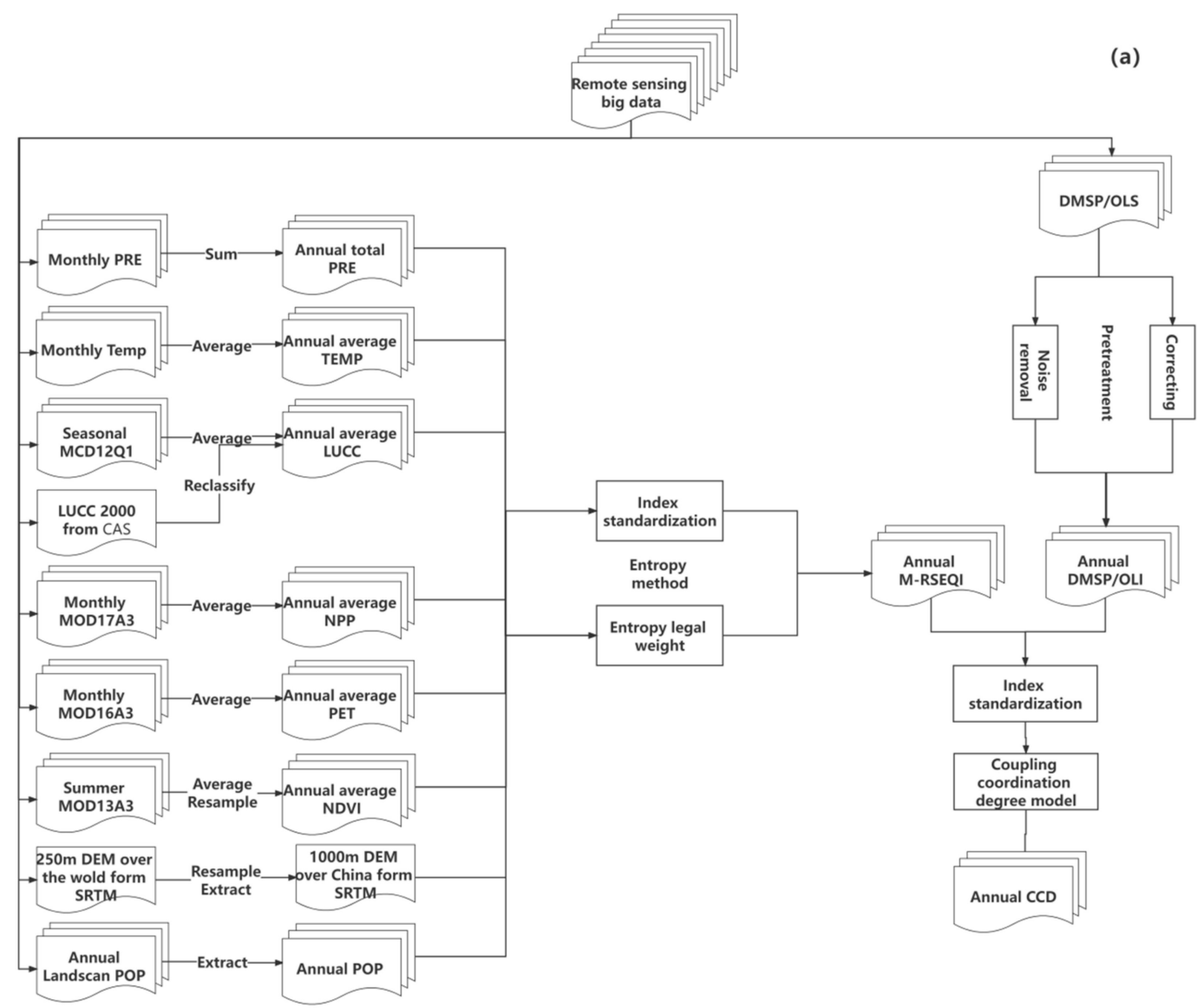

Example for one year (2000-2013)

(b)
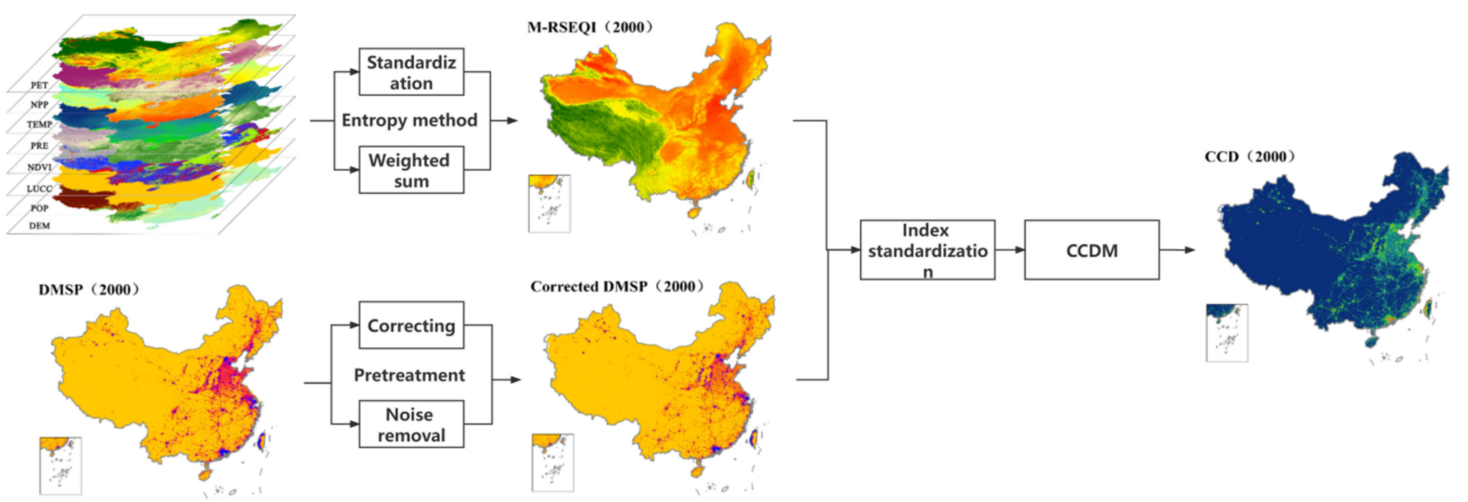

Figure 2. Flowchart of the methods. (a) The flowchart of data processing methods; (b) An example for one year (2000).

Another key point of EEQ assessment is the assessment model. Currently, the main assessment methods include objective methods and subjective methods. Common objective methods include the entropy method (EM) and principal component analysis (PCA), and common subjective methods include grey relation analysis (GRA) and the analytic hierarchy process (AHP) [55]. This study used the EM to calculate the weights of the eight indicators 
in order to eliminate the influence of subjective human factors on the study results. The calculation equations of the EM are as follows:

$$
\begin{gathered}
w_{i j}=\frac{r_{i j}^{+}}{\sum_{i=1}^{n} r_{i j}^{+}} \text {or } w_{i j}=\frac{r_{i j}^{-}}{\sum_{i=1}^{n} r_{i j}^{-}} \\
e_{j}=-k \sum_{i=1}^{n} w_{i j} \ln w_{i j}, k=(\ln n)^{-1} \\
f_{j}=1-e_{j} \\
w_{j}=\frac{f_{j}}{\sum_{j=1}^{m} f_{j}}
\end{gathered}
$$

where $w_{i j}$ is the weight corresponding to the $j$ th indicator of the $i t h$ city, $e_{j}$ is the entropy value of the $j$ th indicator, $f_{j}$ is the redundancy coefficient of the $j$ th indicator, and $w_{j}$ is the weight corresponding to the $j$ th indicator. In this study, $i$ and $j$ have values of 366 and 8 , respectively.

\subsection{Urbanization Assessment Based on DMSP}

Cao's research $[56,57]$ was referred to for the processing of the DMSP nighttime light data, including noise removal and correction. The correction process included the desaturation and continuous correction of different sensors (F15, F16, and F18). Figure 3 shows the change in the total nighttime light value (TNLV) before and after the DMSP nighttime light data correction of the different sensors. The corrected DMSP nighttime light data have good continuity.
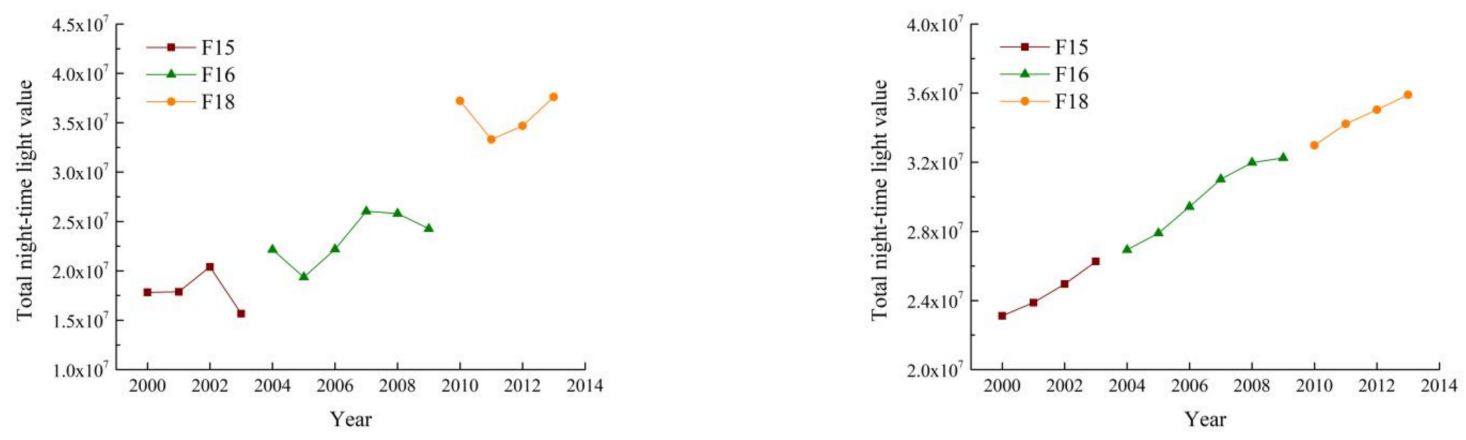

Figure 3. Total nighttime light value (TNLV) of noncorrected DMSP nighttime light data across China (left) and that of corrected DMSP nighttime light data (right).

\subsection{Coupling Coordination Degree Model (CCDM)}

The phenomenon in which two or more systems interact with each other is called coupling, and the coordination degree is the degree of harmony in the interaction between systems [58,59]. The CCDM was used to construct the coupling relationship between the EEQ and urbanization in China from 2000 to 2013. The coupling degree model (CDM) is expressed as

$$
C=\left\{\frac{U \times E}{[(U+E) / 2]^{2}}\right\}^{\frac{1}{2}}
$$

where $C$ is the coupling degree; the larger $C$ indicates a more coordinated relationship of the EEQ and urbanization; $U$ is designated as urbanization; and $E$ is M-RSEQI.

The coupling degree model is a representation of the coordination between the two subsystems. In fact, the size of the subsystem value does not affect the degree of coordina- 
tion. Therefore, we introduced the CCDM based on the CDM, which avoids these issues. The formula of the CCDM is as follows:

$$
D=\sqrt{C \times T}, T=\alpha U+\beta E
$$

where $D$ is the CCD and ranges from 0 to $1 ; T$ is the comprehensive assessment index; and $\alpha$ and $\beta$ are undetermined coefficients, where $\alpha+\beta=1$. In this study, $\alpha$ and $\beta$ were both assumed to be 0.5 .

The CCD was divided into three categories and six subcategories according to the classification criteria in Table 2.

Table 2. Classification standard of the CCD between the EEQ and urbanization based on the classification breakpoints.

\begin{tabular}{cccc}
\hline CCD & Progression Stage & Comparison & Subcategories \\
\hline $0 \leq \mathrm{D}<0.2$ & Uncoordinated & $\mathrm{U}<\mathrm{E}$ & Urbanization lags behind \\
& & $\mathrm{U}>\mathrm{E}$ & Eco-environment lags behind \\
$0.2 \leq \mathrm{D}<0.4$ & Primary coordinated & $\mathrm{U}<\mathrm{E}$ & Urbanization lags behind \\
& & $\mathrm{U}>\mathrm{E}$ & Eco-environment lags behind \\
$0.4 \leq \mathrm{D} \leq 1$ & Coordinated & $\mathrm{U}<\mathrm{E}$ & Urbanization lags behind \\
& & $\mathrm{U}>\mathrm{E}$ & Eco-environment lags behind \\
\hline
\end{tabular}

\subsection{Trend Analysis}

This study used the univariate linear regression model to calculate the annual change trend of the M-RSEQI, urbanization, and the CCD [60-62]. The formula is as follows (the trend of M-RSEQI):

$$
\text { slope }=\frac{n \times \sum_{i=1}^{n}\left(i \times M R S E Q I_{i}\right)-\sum_{i=1}^{n} i \sum_{i=1}^{n} M R S E Q I_{i}}{n \times \sum_{i=1}^{n} i^{2}-\sum_{i=1}^{n} i}
$$

where slope is the slope of the linear regression equation between the M-RSEQI and year in China from 2000 to 2013, $i$ is the time variable, $n$ is the year and is set as 14 in this study, and $M R S E Q I_{i}$ is the $M-R S E Q I$ of the $i t h$ year. When $\mathrm{A}<0$, it indicates that the EEQ is decreasing; when $\mathrm{A}>0$, it indicates that the EEQ is increasing. The absolute value represents the rate of slope change in the M-RSEQI.

\section{Results}

\subsection{M-RSEQI}

\subsubsection{Rationality of M-RSEQI}

The collinear diagnostic indicators in linear regression were used to explore the redundancy of the selected indicators in this study. The variance inflation factor (VIF) and tolerance (TOL) are reciprocal to each other and are commonly used indicators for collinearity diagnosis. When VIF $<10$ or TOL $>0.1$, it indicates that the selected assessment indicators are reasonable [63]. In this study, the pixel values of all eight indicators were extracted and analyzed for redundancy. The diagnosis results are shown in Table 3. The diagnosis results show that the eight indicators that were selected in this study are reasonable, and there is no information redundancy between them.

\subsubsection{Spatiotemporal Changes in M-RSEQI}

As shown in Figure 4a, the areas with obvious improvements in the EEQ were mainly located on the Loess Plateau and on the Greater Khingan Rangeg. The provinces with the most rapid growth trends in the M-RSEQI were Ningxia, Qinghai, and Shaanxi, which had rates of $1.295\left(10^{-3} / \mathrm{a}\right), 1.146\left(10^{-3} / \mathrm{a}\right)$, and $1.105\left(10^{-3} / \mathrm{a}\right)$, respectively (Figure $\left.4 \mathrm{~b}\right)$. 
Coincidently, the areas where the EEQ significantly decreased were mainly located in southern China, especially in the southwest region. Yunnan was the province with the fastest decreasing M-RSEQI trend among all of the provinces, with a trend of $-1.311\left(10^{-3} / \mathrm{a}\right)$, followed by Taiwan and Fujian. The areas where the M-RSEQI remained relatively unchanged were located in the central and northern parts of Xinjiang, the central and western parts of Inner Mongolia, and the Hexi Corridor.

Table 3. Collinearity diagnosis results.

\begin{tabular}{ccc}
\hline Indicator & VIF & TOL \\
\hline PRE & 8.097 & 0.123 \\
TEMP & 9.411 & 0.106 \\
NPP & 5.758 & 0.174 \\
NDVI & 5.922 & 0.169 \\
DEM & 2.975 & 0.336 \\
LUCC & 4.095 & 0.244 \\
POP & 1.349 & 0.741 \\
PET & 2.634 & 0.380 \\
\hline
\end{tabular}
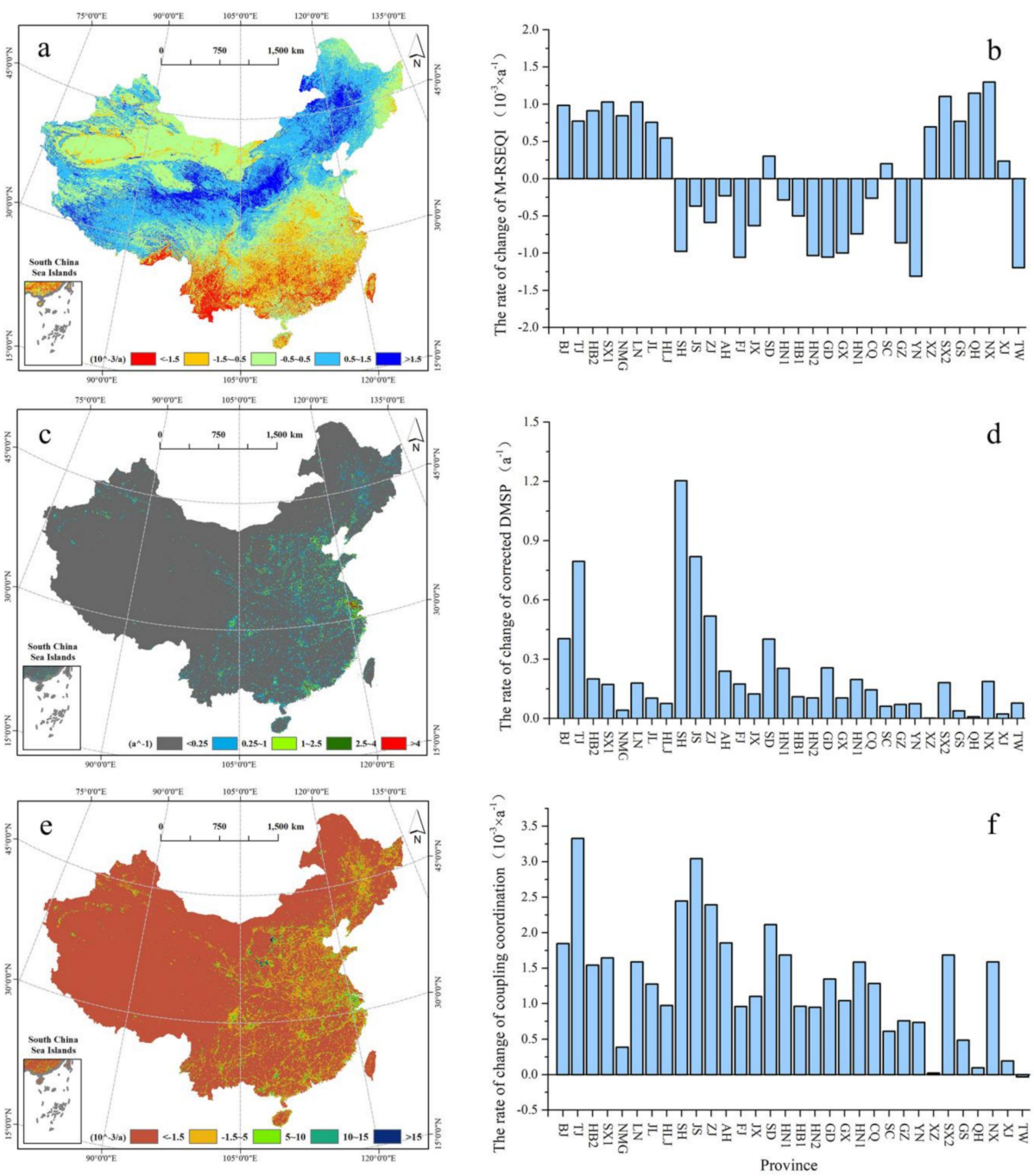

Figure 4. The change trend distribution of M-RSEQI (a), DMSP (c), and CCD (e) in China from 2000 to 2013 and the average trend value of M-RSEQI (b), DMSP (d), and CCD (f) for each province. 


\subsubsection{M-RSEQI in Different Ecosystems}

Figure 5 shows that China's EEQ showed a fluctuating change but tended to remain stable in different ecosystems from 2000 to 2013. Among the six ecosystems, the M-RSEQI of the water area was the highest (Figure 5a), reaching 0.346 and indicating that the ecoenvironment of the water area was the best. The overall average value of the built-up ecosystem was the lowest (0.200), which indicates that the development of urbanization would inevitably affect the eco-environment. For all of the ecosystems, the M-RSEQI in 2007 was the highest among all of the years. We speculated that the reasons leading to the growth of China's M-RSEI in 2007 could be diversified. This could be related to the environmental protection policies that were formulated by the Chinese government to welcome the arrival of the Olympic Games. As shown in Figure 4a, the areas where the EEQ in China has improved are mainly concentrated in the Loess Plateau, and the effectiveness of China's environmental governance on the Loess Plateau in recent years is prominent.
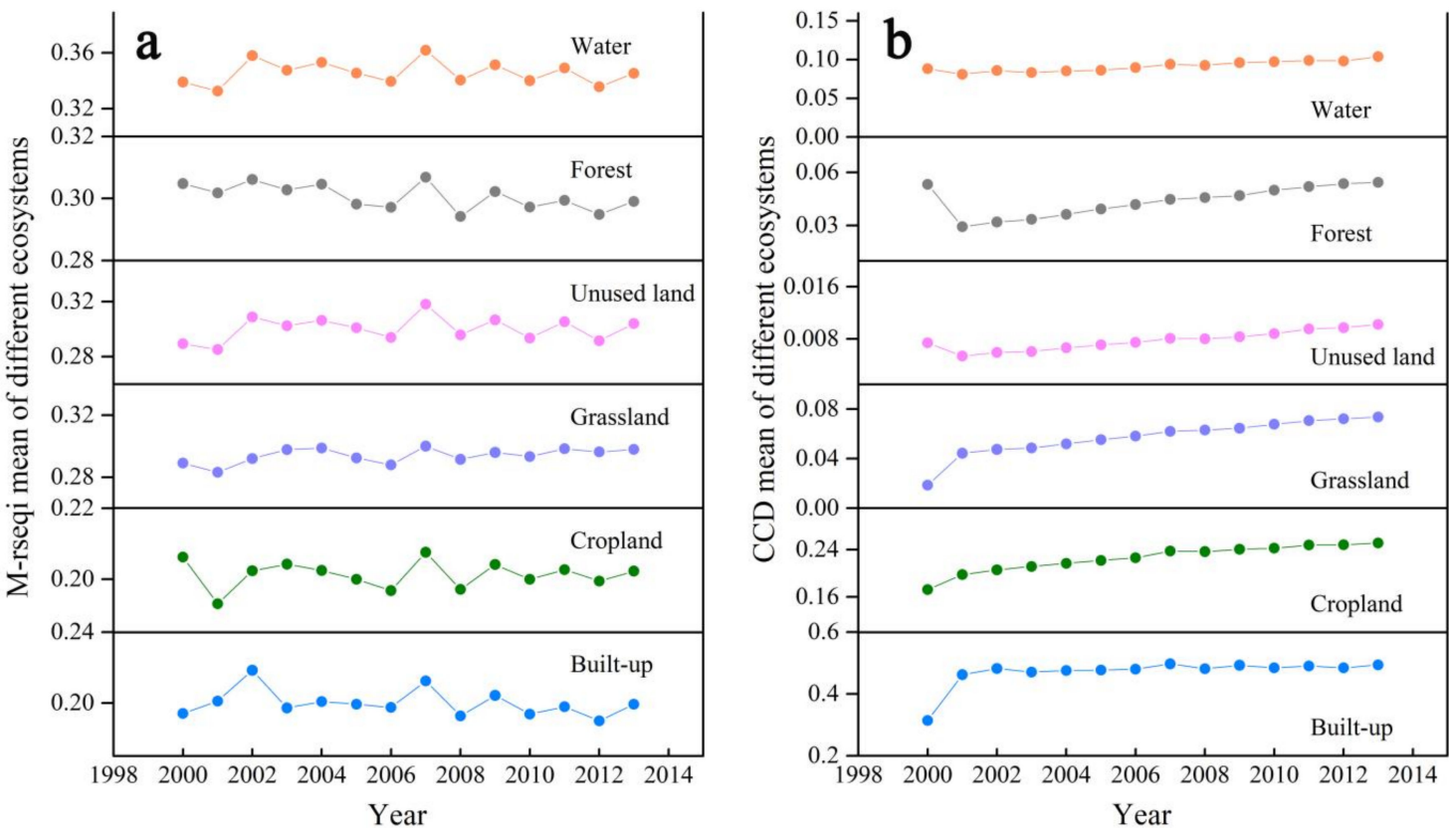

Figure 5. Annual changes in the (a) M-RSEQI and (b) CCD in China in different ecosystems from 2000 to 2013.

Figure 6a shows that the change in the M-RSEQI of the water ecosystem was the largest from 2000 to 2013, ranging from 0.333 to 0.362 , which shows that the eco-environment of water in China greatly improved during this period. The M-RSEQI standard deviation for water was 0.135 , which was the largest among all of the ecosystems (Figure 6, right). The interior of the water ecosystem is relatively complex and includes lakes, rivers, reservoirs, ponds, glaciers, and wetlands [64]. The standard deviations of the cropland and built-up areas were small, with values of 0.035 and 0.040 , respectively, indicating that the EEQ was relatively stable.

\subsection{Urbanization}

\subsubsection{Validity of Corrected DMSP}

Corrected DMSP data were fitted with AHF [53] (anthropogenic heat flux) data to explore the validity of the corrected DMSP nighttime light data in this article (Figure 7). From the four fitting equations, it can be seen that the light intensity was positively correlated with $\mathrm{AHF}$, and that $\mathrm{R}^{2}$ was higher than 0.6 , indicating a larger light intensity with a larger number of people, which was consistent with the actual situation. Therefore, the DMSP nighttime light data that were corrected in this study had high validity. 

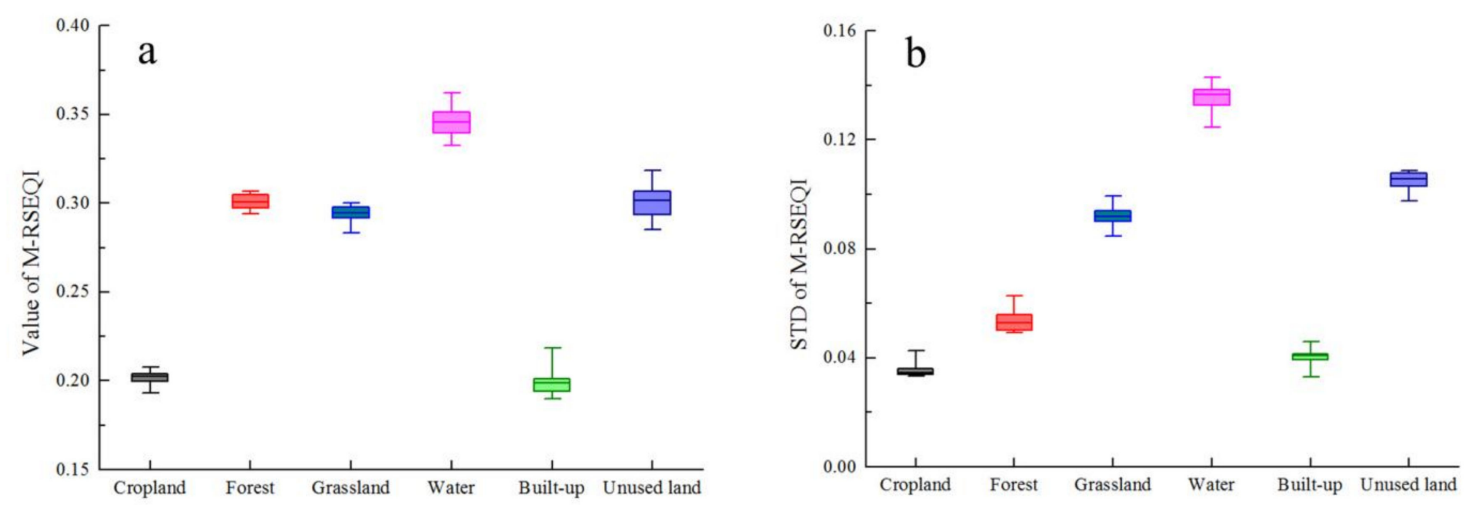

Figure 6. The mean (a) and standard deviation (b) of the M-RSEQI in different ecosystems in China from 2000 to 2013.
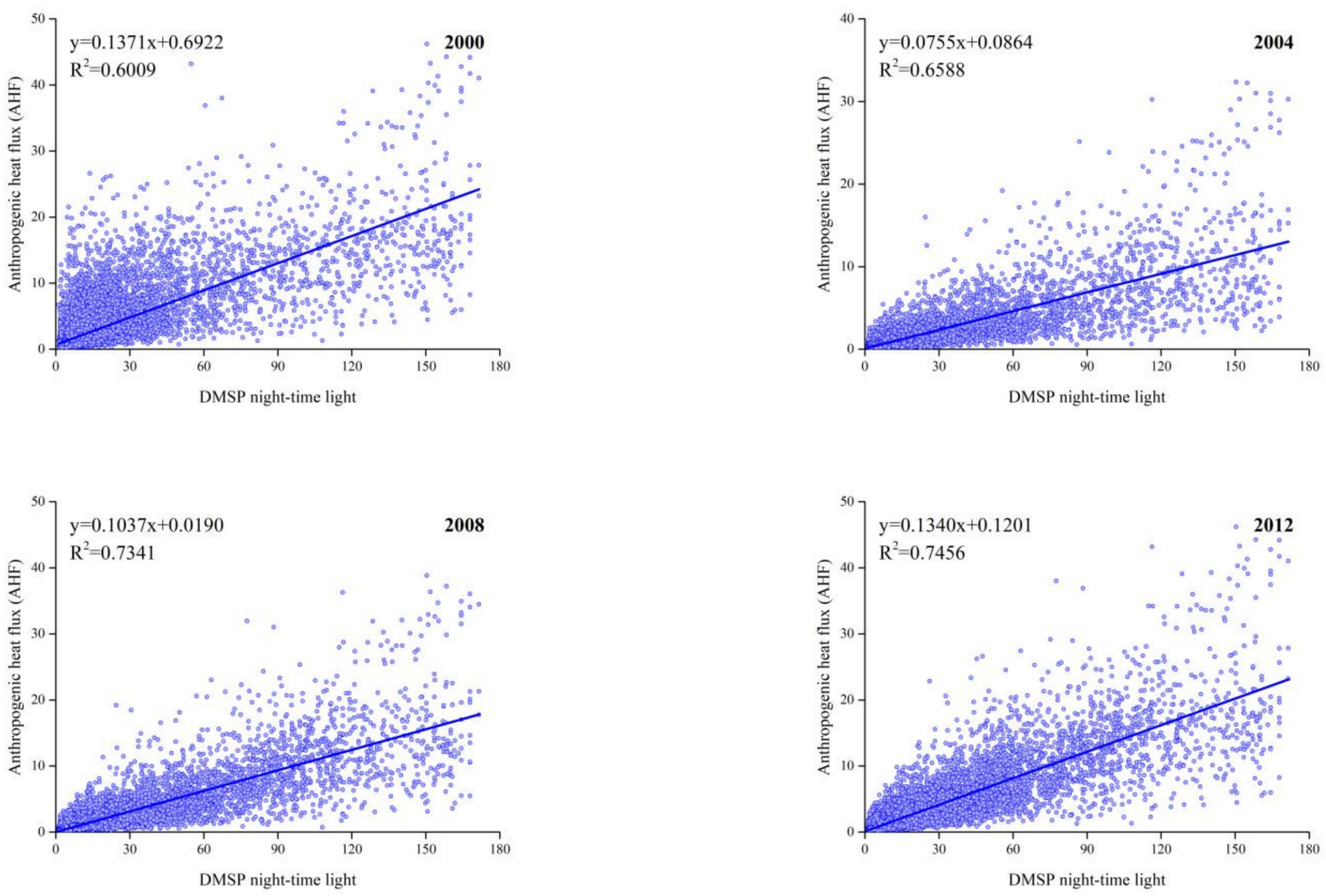

Figure 7. Scatter plot of corrected DMSP nighttime light data and AHF data in 2000, 2004, 2008, and 2012. The blue line represents the relationship obtained by fitting DMSP and AHF.

Figure 8 shows the corrected DMSP night light data from 2001 to 2013 in China. As seen in Figure 8, China's nighttime light showed a spatial distribution pattern of "high in the East and low in the west", and the nighttime light of China's three major urban agglomerations (Beijing Tianjin Hebei Urban Agglomeration, Yangtze River Delta Urban Agglomeration, and Pearl River Delta Urban Agglomeration) were the brightest. The dense road network in central and eastern China has greatly promoted the urbanization process in the region. As of 2019, China's central and eastern region is home to $97.59 \%$ of China's total population, and it contains $87.27 \%$ of China's GDP [65]. Secondly, from 2001 to 2013, the nighttime light in China was gradually brightened, which shows that China's urbanization has continued to develop over the past 14 years, which is consistent with the conclusions seen in Figure 7. 


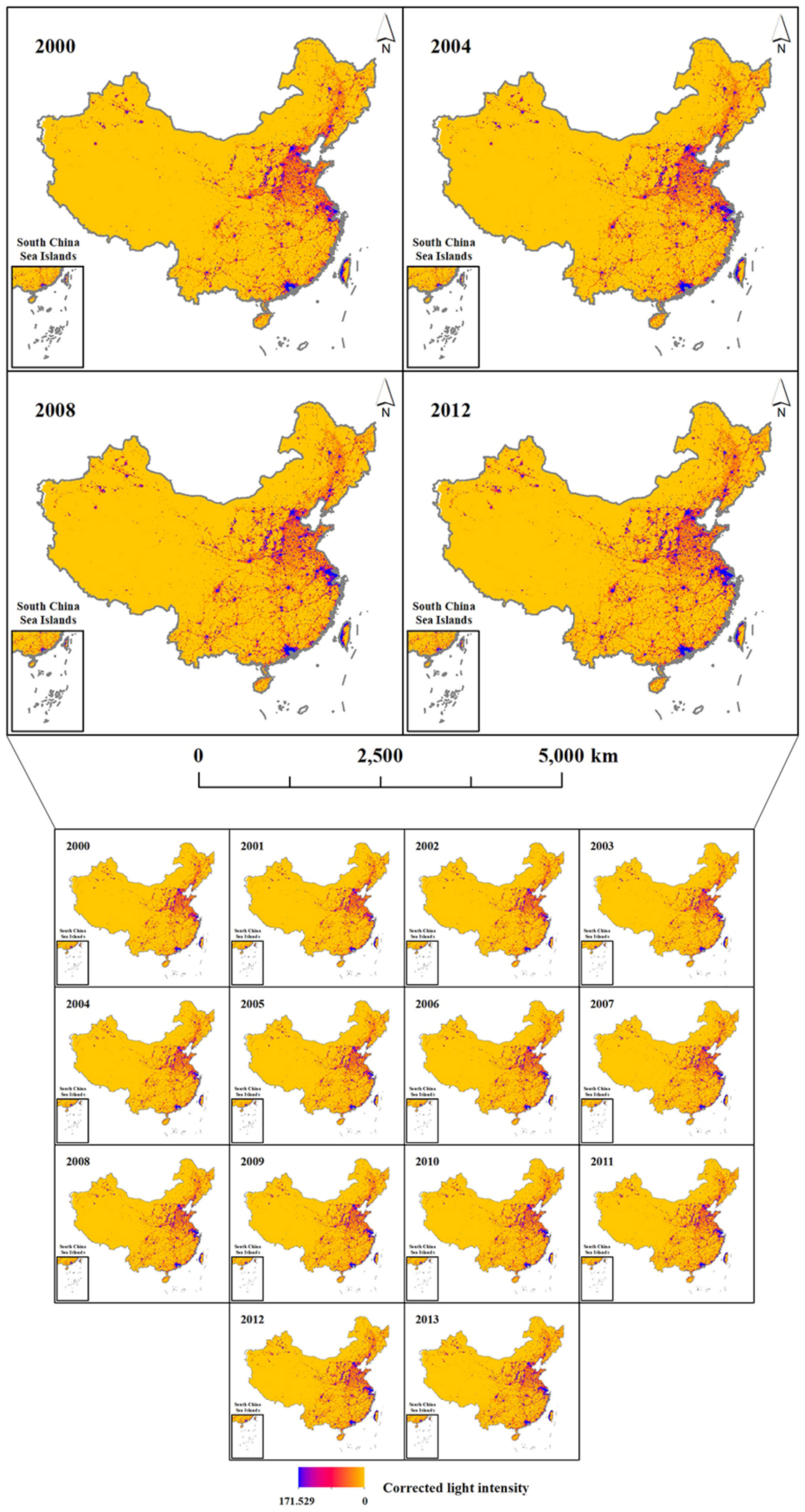

Figure 8. Spatial distribution map of corrected DMSP nighttime light data in China from 2000 to 2013.

\subsubsection{Spatiotemporal Changes in Urbanization}

As shown in Figure 4c, urbanization development in China from 2000 to 2013 shows the characteristics of "fast in the east and slow in the west". Among all of the provinces (including municipalities directly under the Central Government), Shanghai had the fastest urbanization development process, with a rate of $1.203\left(10^{-3} / \mathrm{a}\right)$, followed by Jiangsu (0.819) and Tianjin (0.794) (Figure 4d). During this period, the speed of urbanization in the Tibet Autonomous Region (0.002) was the slowest, followed by Qinghai (0.008) and Xinjiang (0.022), which was strongly related to geography. Poor living conditions and rare population centers hindered the urbanization development of these provinces. In contrast, 
Shanghai and Tianjin, China's two major ports, are at the forefront of economic reform and opening up. With the support of national policies and advanced technology, urbanization has developed rapidly. Jiangsu Province, which is located on the Yangtze River Delta, is the only province where all of the prefecture-level cities have entered the top 100 in China.

\section{3. $C C D$}

\subsubsection{Spatiotemporal Changes in CCD}

Figure 9 shows the spatial distribution of CCD in China from 2001 to 2013. It can be seen that similar to DMSP nighttime light, China's CCD presented a spatial distribution pattern of "high in the east and low in the west", and the three major urban agglomerations had the highest CCD. Secondly, it can be seen from Figure 9 that China's CCD has gradually increased from 2001 to 2013, which is consistent with the conclusion in Section 4.2.1.

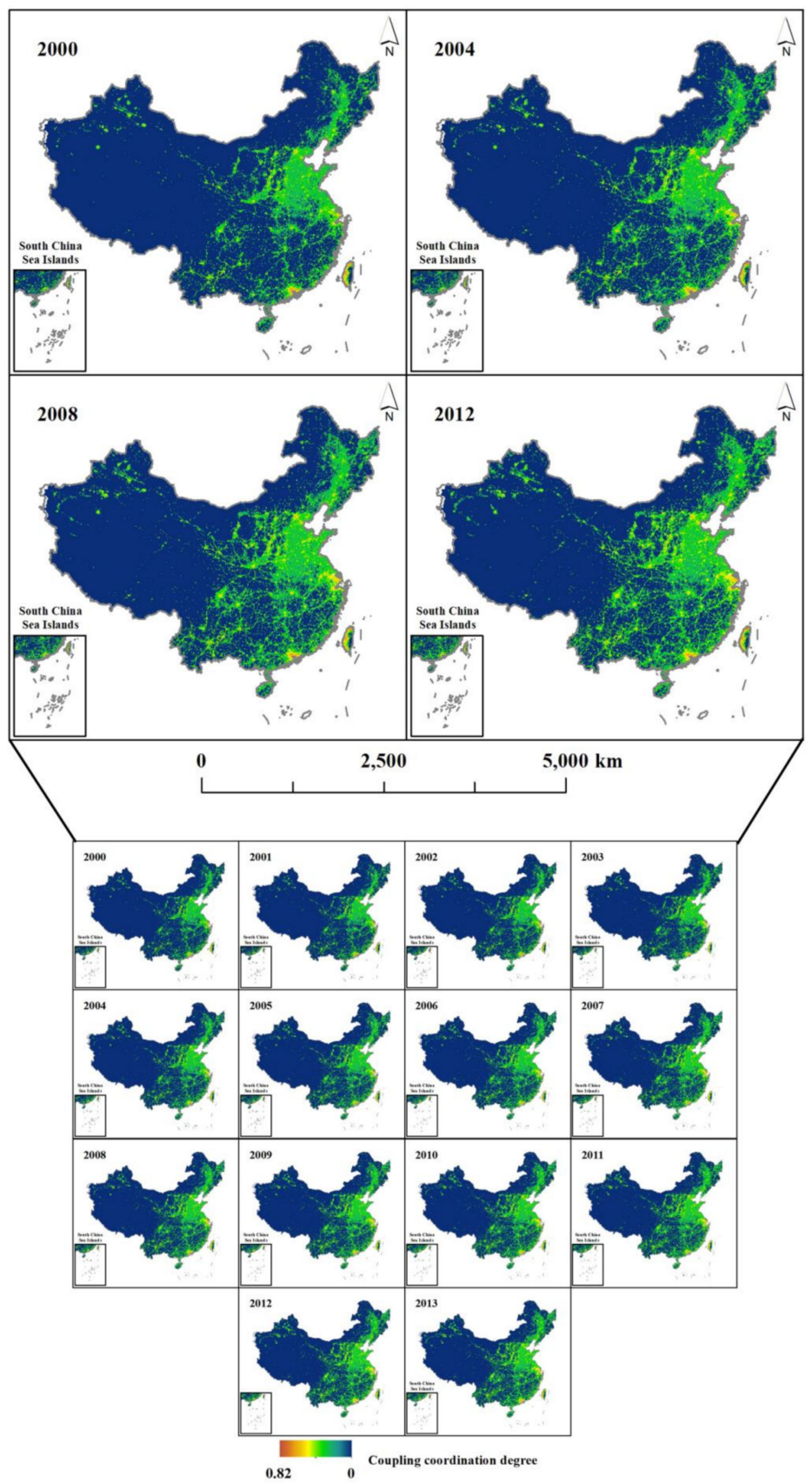

Figure 9. Spatial distribution map of CCD data in China from 2000 to 2013. 
Figure $4 \mathrm{e}$ shows that the trends for the CCD between the EEQ and urbanization had the characteristic of "fast in the east and slow in the west". This is similar to the characteristics that were observed in the urbanization trends. This indicates that the CCD was greatly affected by urbanization development. Among all of the provinces, Tianjin had the fastest growth in CCD, with a trend of $3.326\left(10^{-3} / \mathrm{a}\right)$ (Figure $\left.4 \mathrm{f}\right)$. This was closely related to the industrial structure adjustment policy of Tianjin. As shown in Figure 5, from 2000 to 2013, the M-RSEQI of Tianjin increased significantly, and it was also one of the provinces with the fastest trend of urbanization development. Among all of provinces, Taiwan Province showed a downward trend in CCD changes, which was likely caused by the continuous decline in its urbanization rate. The main reason was that from 2000 to 2013, the urbanization of Taiwan Province was in a stagnation state, while its EEQ showed a downward trend (Figure 4 b).

As shown in Figure 10, the CCD of provincial capital cities, including municipalities directly under the central government, increased significantly from 2000 to 2013 . Although Figure 10 presents that the CCD of almost all cities has shown an increasing trend, it also reflects that there are significant spatial differences in their changes. Among them, the CCD of cities in central and eastern China, represented by Beijing, Shanghai, Guangzhou, and Hangzhou, have grown rapidly, while the cities of western China, represented by Lhasa, Urumqi, and Xining, have experienced slower growth, which is consistent with the conclusion obtained from Figure 4e. Secondly, we also found an interesting phenomenon. Taiwan Province, as a typical eastern coastal area of China, demonstrates rare CCD growth. Based on the above conclusion that rapid urbanization has promoted regional CCD growth, we speculate that the main reason is the slow development of urbanization in Taiwan Province in recent years, which has also inhibited Taiwan's CCD growth.

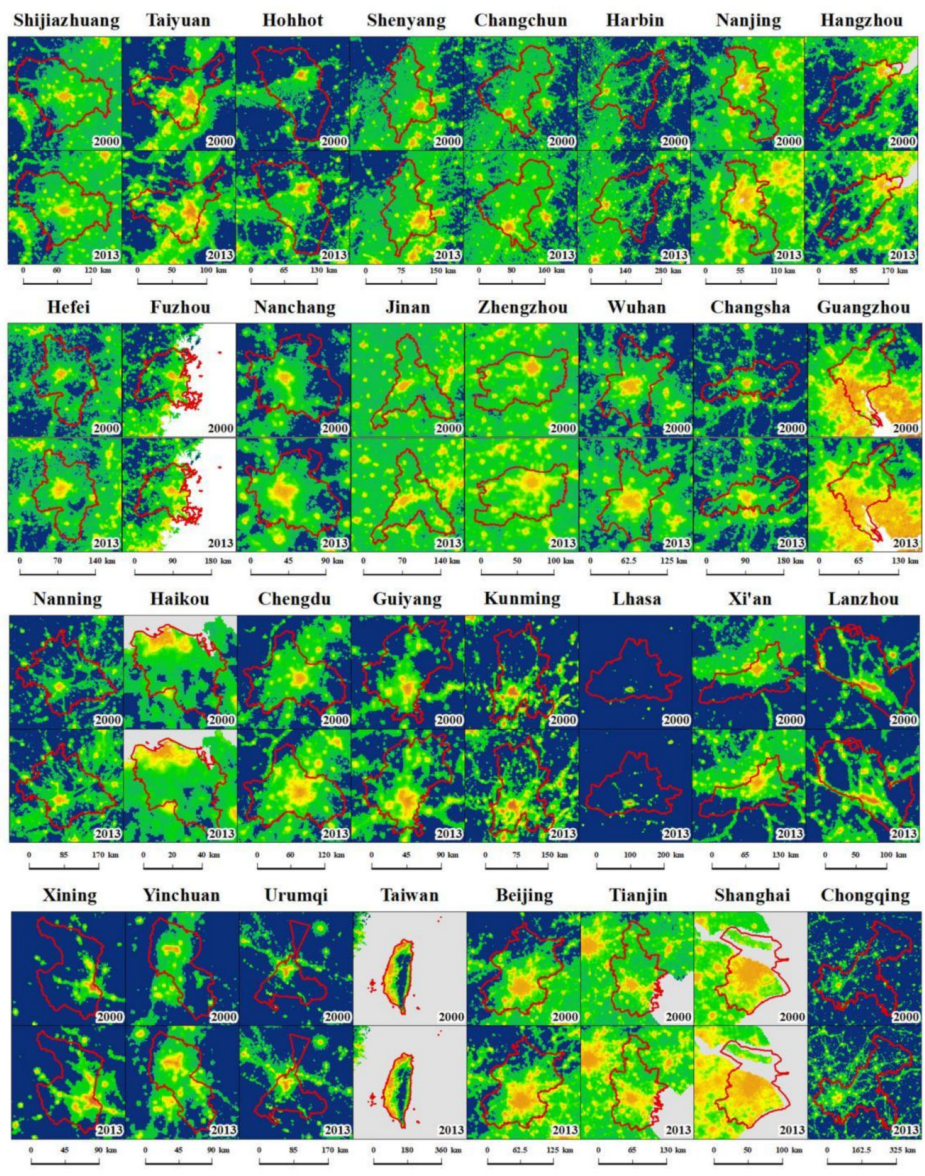

Figure 10. CCD of 28 provincial capital cities and 4 municipalities directly under the central government in 2000 and 2013. 
According to the grading standards in Table 2, the CCD of all of the cities in China from 2000 to 2013 were classified. Figure 11 shows that cities with higher CCD in China were mainly distributed in the North China Plain and in the southeastern coastal areas. From 2000 to 2013, most cities in China were in an uncoordinated state, which was concentrated in the central and western regions of China. In addition, there were almost no uncoordinated or primary coordinated cities with EEQ that lagged behind. This indicates that there was a large imbalance in the spatial distribution of urbanization development, which extended to most of China's uncoordinated cities from 2000 to 2013.

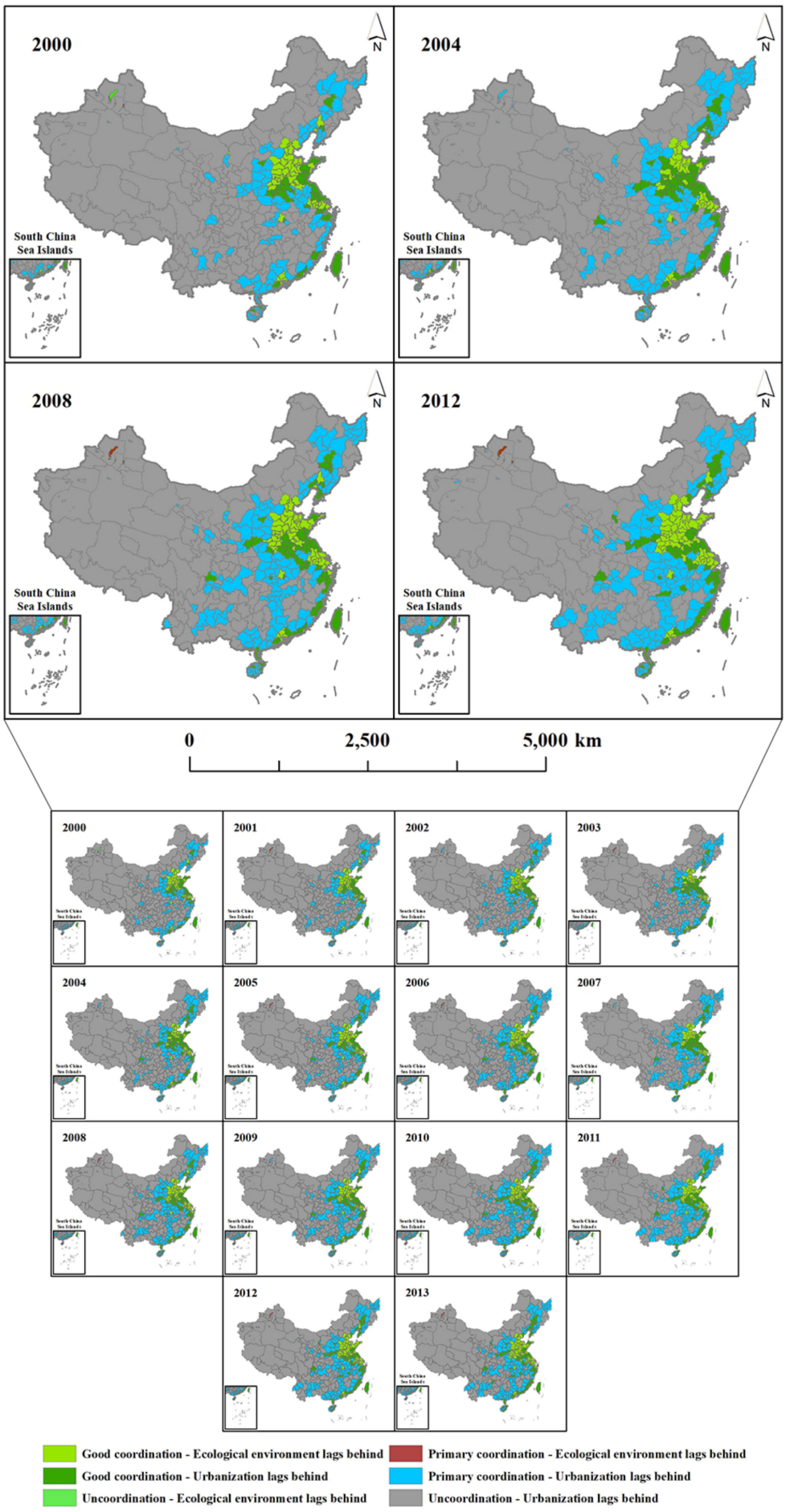

Figure 11. China's CCD classification map from 2000 to 2013. 
Figure 12 shows that the number of uncoordinated cities decreased each year, while the number of primary coordinated and coordinated cities increased. From 2000 to 2013, the number of coordinated cities increased from 83 to 125 . Simultaneously, the number of uncoordinated cities decreased from 181 to 110 . With the continuous development of China's urbanization, the pace of urbanization gradually matched the EEQ, while the CCD also constantly improved. Since 2000, the number of Subtype VI (uncoordinated: urbanization lags behind) cities was the largest, whilst the number of Subtype IV (primary coordinated: urbanization lags behind) $\mathrm{b}$ cities became the largest in 2013. This shows that the level of urbanization in China was lower than the EEQ from 2000 to 2013. In summary, the coupling law of the EEQ and urbanization in China was "uncoordinated to primary coordinated. primary coordinated to coordinated, and with the characteristic of "urbanization lags behind EEQ" evolving into "EEQ lags behind urbanization". In the future, the CCD of cities in China will go through the process of "Type III to Type II to Type $I^{\prime \prime}$. When the CCD between the EEQ and urbanization of most cities in China reaches Type $\mathrm{I}$, the entire CCD development process will be in a stable or circular development stage.

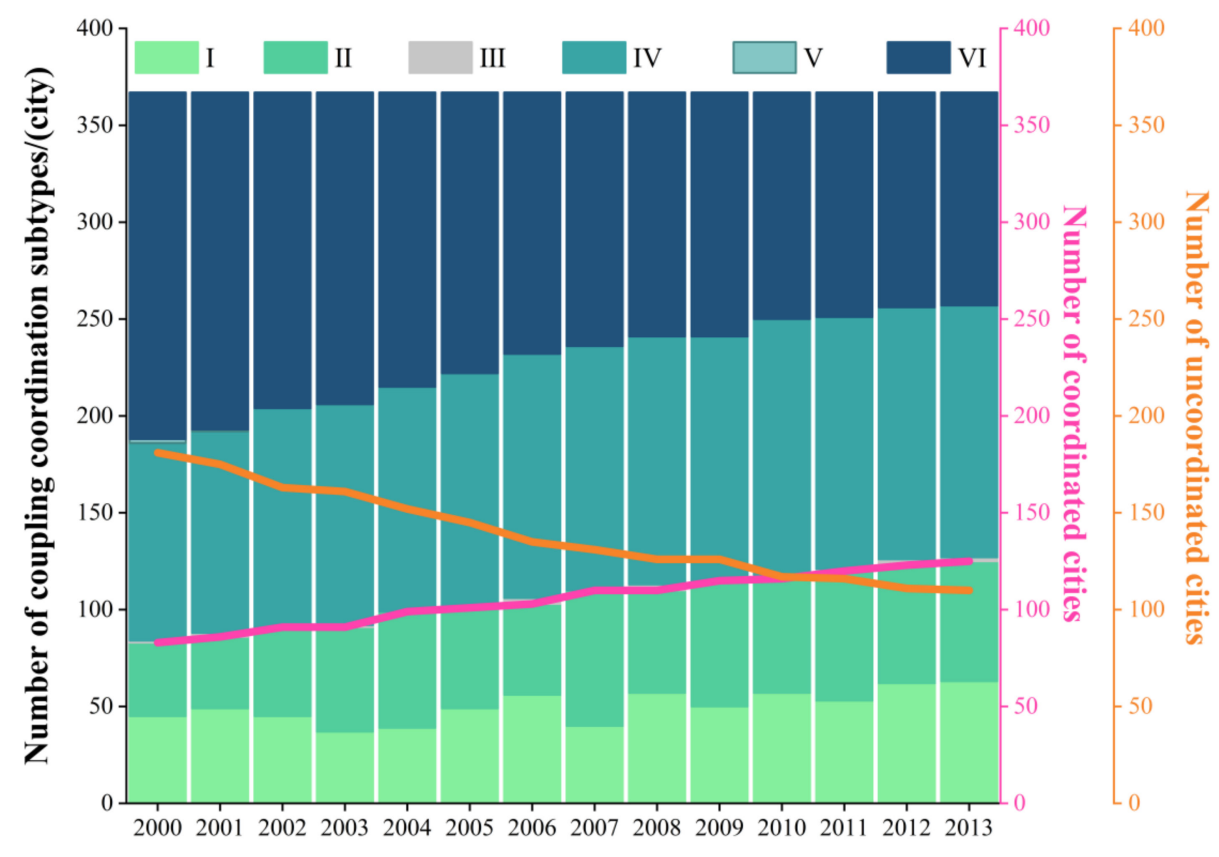

Figure 12. The statistical graph of the number of cities with different CCD subtypes. (I) Coordinated: EEQ lags behind. (II) Coordinated: urbanization lags behind. (III) Primary coordinated: EEQ lags behind. (IV) Primary coordinated: urbanization lags behind. (V) Uncoordinated: EEQ lags behind. (VI) Uncoordinated: urbanization lags behind.

\subsubsection{Change Characteristics of the CCD in Different Ecosystems}

Figure $5 \mathrm{~b}$ shows that built-up ecosystems $(0.470)$ had the highest $\mathrm{CCD}$ among the six ecosystems. The CCD value of unused land (0.008) was the lowest. However, the CCD values of forest, grassland, and water that had higher EEQ levels were not higher, which indicates that the decisive factor of the CCD came from urbanization. This result is consistent with the conclusion in Section 4.3.1. In addition, the CCD values of the six ecosystems maintained a steady increasing trend from 2000 to 2013, which was closely related to the continuous development of urbanization in China during this period.

\section{Discussion}

\subsection{Coupling Mechanism Analysis}

The above analysis of the results shows that at this stage, the development of urbanization has a decisive influence on the CCD. To explain this phenomenon, the coupling 
mechanism between China's urbanization and EEQ was explored using a combination of mathematics and geometry. The change rates of the tangent plane in the two dimensions of urbanization and M-RSEQI were used to characterize the degree of influence of urbanization and the EEQ in terms of coupling and the coordination degree. The tangent plane is calculated by

$$
C C D-C C D_{0}=F_{U}^{\prime}\left(U-U_{0}\right)+F_{E}^{\prime}\left(E-E_{0}\right)
$$

where $C C D$ is the coupling coordination degree; $F^{\prime} U$ and $F^{\prime}{ }_{E}$ are the partial derivatives of urbanization and RSEI-2, respectively; $C C D_{0}, U_{0}$, and $E_{0}$ are the mean values of the CCD, urbanization, and EEQ in 2013, which are 0.445, 0.026, and 0.216, respectively.

Figure 13a shows the spatial distribution of the CCD trends in China from 2001 to 2013. The blue and red lines represent the average trend values of nighttime light and CCD in latitude and longitude, respectively. We can see that the scale of latitude and longitude, the trends of CCD and nighttime light have a high degree of consistency in terms of the spatial distribution, which shows that the changes in urbanization have profoundly affected the changes in CCD. Figure 13b,c show the correlation between the average trend value of CCD and nighttime light in latitude and longitude, respectively. It can be seen that there is a significant correlation $(p<0.001)$ between the two values at the latitude and longitude scale.

Urban areas are often used to evaluate a region's level of urbanization [66,67]. Therefore, we extracted the land use and land cover (LULC) [68] data for urban areas in China in 2001 and 2013, calculated the urban sprawl index (USI) of all cities in China, divided all of the cities into five categories according to the classification standard in Figure 13f, and finally counted the annual CCD values of these five types of cities and the 371 cities in China. It can be seen from Figure $13 \mathrm{f}$ that the CCD value of most cities showed a continuous upward trend (gray broken line). Most importantly, we found that the city with the highest USI had the highest CCD growth rate, reaching $0.494\left(10^{-3} / a\right)$. On the contrary, the city with the slowest USI had the lowest CCD growth rate, which was $0.183\left(10^{-3} / \mathrm{a}\right)$. This also confirms the abovementioned speculation that urbanization has promoted the development of CCD.

Figure 13d,e show that in 2013, the growth rate of the CCD in the urbanization component was 2.659, while the increase in the M-RSEQI component was only 0.316, indicating that in 2013, the degree of impact that urbanization had on the CCD was approximately 8.4 times larger than that of the EEQ. Therefore, this explains that in 2013, the decisive factor that was affecting the CCD was the development of urbanization.

\subsection{Limitations and Prospects}

Although this study has made some progress compared to previous studies and has drawn some meaningful conclusions, this study also has some limitations. First, it should be noted that although this study and previous studies [69] show that using nighttime light data as an indicator of urbanization is theoretically reasonable, it cannot be ignored that nighttime light only has certain advantages in characterizing the intensity of regional night human activities and cannot provide direct evidence of daytime urbanization intensity. Because of this situation, people mainly work in urban areas during the day and return to the suburbs to live and rest at night, which will lead to a certain difference between the level of urbanization that is assessed by nighttime light data and the actual level of urbanization. Secondly, since NASA suspended DMSP night light data updates in 2013, the main limitation of this study is that it is temporarily unable to confirm our theoretical methods and conclusions using the latest data. In the future, we will work to correct DMSP and VIIRS nighttime light data to help us carry out longer-term serial studies on this topic.

In addition, there are great differences in the EEQ (ecological footprint) between urbans areas and the suburbs. The EEQ of urban areas will generally be lower than that of suburbs because the higher population density in urban areas will produce higher anthropogenic heat emissions and other pollutants. However, we believe that the level of "sustainable development" comprises the integration of EEQ and urbanization because the 
goal of "sustainable development" is benign social and economic development, i.e., we need to pay attention to the protection of the ecological environment while pursuing social and economic development. Therefore, as shown by the CCDM, the level of "sustainable development" depends on the coupling coordination level of EEQ and urbanization.
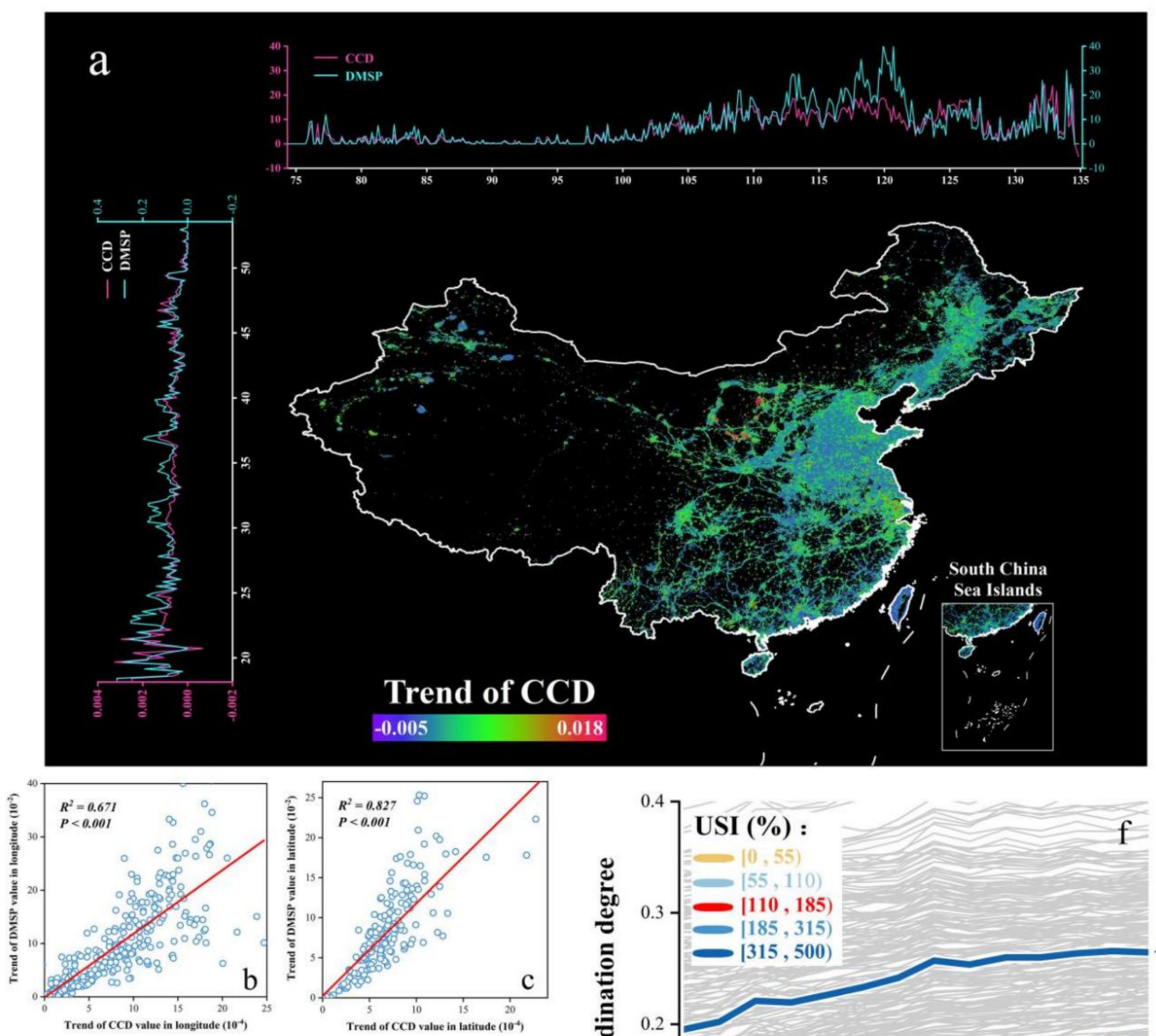

$\mathrm{d}$
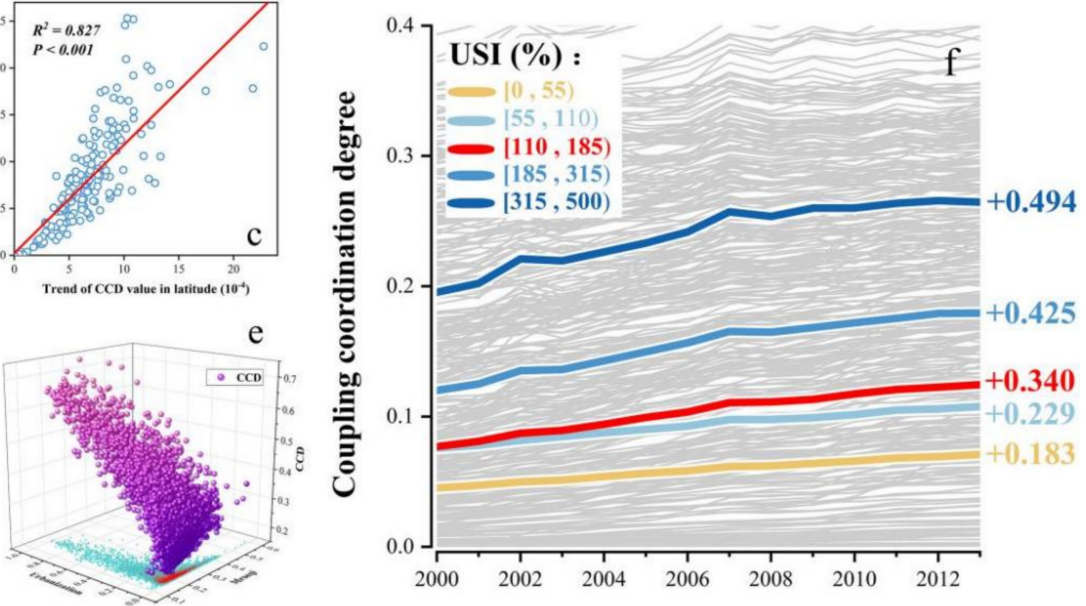

Figure 13. 3D scatter diagram of M-RSEQI, urbanization, and CCD in 2013 and 3D function diagram of the CCD model. (a) shows the spatial distribution of the CCD trends in China from 2001 to 2013; $(\mathbf{b}, \mathbf{c})$ show the correlation between the average trend value of CCD and nighttime light in latitude and longitude; (d,e) show that in 2013, the growth rate of the CCD in the urbanization component was 2.659; (f) the CCD value of most cities showed a continuous upward trend (gray broken line).

\section{Conclusions}

China's rapid urbanization has led to serious eco-environmental problems. With regard to the increasingly severe eco-environmental situation, it is important to understand the relationship between China's EEQ and urbanization for the realization of the 2030 agenda (Transforming Our World: The 2030 Agenda for Sustainable Development) [21] Therefore, based on multisource remote sensing data and EM, we designed a spatiotemporal universal EEQ assessment system and used the CCDM in physics to construct the coupling 
relationship between the EEQ and urbanization in China from 2000 to 2013. Through this study, some meaningful conclusions are drawn:

1. The decisive factor affecting the CCD was urbanization development in 2013. The impact that the degree of urbanization had on the CCD was approximately 8.4 times higher than that of the EEQ.

2. From 2000 to 2013, the urbanization development of China showed the characteristics of "fast in the east and slow in the west" over the course of the past 14 years. The CCD between the EEQ and urbanization in China showed the characteristic of "strong in the east, weak in the west".

3. Most of China's cities were in an uncoordinated state and were concentrated in the central and western regions of China. The coupling pattern of EEQ and urbanization in China evolved from "uncoordinated cities into coordinated cities, with the characteristic of "urbanization lags behind EEQ" evolving into "EEQ lags behind urbanization".

Author Contributions: Conceptualization, D.X. and H.L.; methodology, D.X. and J.C.; software, S.X. and J.G.; validation, J.C. and H.F.; formal analysis, D.X. and H.F.; investigation, D.X.; resources, Y.W., J.X. and S.W.; data curation, D.X.; writing-original draft preparation, D.X.; writing-review and editing, H.L., F.Y. and R.Z.; visualization, S.X.; supervision, J.C.; project administration, M.L. and J.H.; funding acquisition, H.F. and J.G. All authors have read and agreed to the published version of the manuscript.

Funding: This research was funded by the Youth Program of National Natural Science Foundation of Zhejiang Province grant number LQ21D060001, Hainan Provincial Natural Science Foundation of China grant number 420RC673, 2021 Science and Technology Plan Project of Zhejiang Meteorological Bureau grant number 2021YB07, Fengyun Application Pioneering Project grant number FY-APP2021.0105, and the National Natural Science Foundation of China grant number 42176180. And The APC was funded by the Youth Program of National Natural Science Foundation of Zhejiang Province grant number LQ21D060001.

Institutional Review Board Statement: Not applicable.

Informed Consent Statement: Not applicable.

Data Availability Statement: Not applicable.

Acknowledgments: This work is supported by the Youth Program of National Natural Science Foundation of Zhejiang Province (LQ21D060001), Hainan Provincial Natural Science Foundation of China grant number 420RC673, 2021 Science and Technology Plan Project of Zhejiang Meteorological Bureau (2021YB07), Fengyun Application Pioneering Project grant number FY-APP-2021.0105, and the National Natural Science Foundation of China grant number 42176180.

Conflicts of Interest: The authors declare no conflict of interest.

\section{References}

1. Shan, G.; Xianjin, H. Performance Evaluation of Eco-construction Based on PSR Model in China from 1953 to 2008. J. Nat. Resour. 2010, 25, 341-350.

2. Sun, D.; Zhang, J.; Zhu, C. An Assessment of China's Ecological Environment Quality Change and Its Spatial Variation. Acta Geogr. Sin. 2012, 67, 1599-1610.

3. McKinney, M.L. Effects of urbanization on species richness: A review of plants and animals. Urban Ecosyst. 2008, 11, 161-176. [CrossRef]

4. Xiuxing, Y. An Assessment of China's Ecological Environment Quality Change and the Spatial Variation. Environ. Life 2014, 9X, 249.

5. Wei, Y.L.; Bao, L.J.; Wu, C.C.; He, Z. Assessing the effects of urbanization on the environment with soil legacy and current-use insecticides: A case study in the Pearl River Delta, China. Sci. Total Environ. 2015, 514, 409-417. [CrossRef]

6. Liu, X.; Ma, L.; Li, X.; Ai, B.; Li, S.; He, Z. Simulating urban growth by integrating landscape expansion index (LEI) and cellular automata. Int. J. Geogr. Inf. Sci. 2014, 28, 148-163. [CrossRef]

7. Zhu, J. The 2030 Agenda for Sustainable Development and China's implementation. Chin. J. Popul. Resour. Environ. 2016, 15, 142-146. [CrossRef] 
8. Wang, S.-X.; Yao, Y.; Zhou, Y. Analysis of Ecological Quality of the Environment and Influencing Factors in China during 2005-2010. Int. J. Environ. Res. Public Health 2014, 11, 1673-1693. [CrossRef]

9. Du, W. Research on the Evaluation Index of Air Pollution Control Audit Based on PSR Model; IOP Conference Series: Earth and Environmental Science; IOP Publishing: Bristol, UK, 2020; Volume 514.

10. McDonald Michael, E. EMAP Overview: Objectives, Approaches, and Achievements; Monitoring Ecological Condition in the Western United States; Springer: Dordrecht, The Netherlands, 2000; pp. 3-8.

11. Smith, E.R. An Overview of EPA's Regional Vulnerability Assessment (ReVA) Program. Environ. Monit. Assess. 2000, 64, 9-15. [CrossRef]

12. US Forest Service. Forest Service Resource Inventories: An Overview. 1992. Available online: https://www.fs.usda.gov/ treesearch/pubs/123 (accessed on 23 December 2021).

13. Ahmed, Z.; Wang, Z.; Mahmood, F.; Hafeez, M.; Ali, N. Does globalization increase the ecological footprint? Empirical evidence from Malaysia. Environ. Sci. Pollut. Res. 2019, 26, 18565-18582. [CrossRef]

14. Shah, S.A.A.; Zhou, P.; Walasai, G.; Mohsin, M. Energy security and environmental sustainability index of South Asian countries: A composite index approach. Ecol. Indic. 2019, 106, 105507. [CrossRef]

15. Xu, C.; Wang, S. A comprehensive quantitative evaluation of new sustainable urbanization level in 20 Chinese urban agglomerations. Sustainability 2016, 8, 91. [CrossRef]

16. $\mathrm{Xu}, \mathrm{D}$.; Hou, G. The Spatiotemporal Coupling Characteristics of Regional Urbanization and Its Influencing Factors: Taking the Yangtze River Delta as an Example. Sustainability 2019, 11, 822. [CrossRef]

17. Zhang, W.; Wang, M. Spatial-temporal characteristics and determinants of land urbanization quality in China: Evidence from 285 prefecture-level cities. Sustain. Cities Soc. 2018, 38, 70-79. [CrossRef]

18. Elmqvist, T.; Fragkias, M.; Goodness, J.; Güneralp, B.; Marcotullio, P.J.; McDonald, R.I.; Parnell, S.; Schewenius, M.; Sendstad, M.; Seto, K.C.; et al. Urbanization, Biodiversity and Ecosystem Services: Challenges and Opportunities: A Global Assessment; Springer Nature: Dordrecht, The Netherlands, 2013.

19. Shao, Z.; Ding, L.; Li, D.; Altan, O.; Huq, E.; Li, C. Exploring the Relationship between Urbanization and Ecological Environment Using Remote Sensing Images and Statistical Data: A Case Study in the Yangtze River Delta, China. Sustainability 2020, 12, 5620. [CrossRef]

20. Chen, W.; Zhang, Y.; Pengwang, C.; Gao, W. Evaluation of Urbanization Dynamics and its Impacts on Surface Heat Islands: A Case Study of Beijing, China. Remote Sens. 2017, 9, 453. [CrossRef]

21. Estoque, R.C. A review of the sustainability concept and the state of SDG monitoring using remote sensing. Remote Sens. 2020, 12, 1770. [CrossRef]

22. $\mathrm{Xu}, \mathrm{H}$. Remote Sensing Evaluation Index of Regional Ecological Environment Changes. China Environ. Sci. $2013,33,889-897$.

23. Shan, W.; Jin, X.; Ren, J.; Wang, Y.; Xu, Z.; Fan, Y.; Gu, Z.; Hong, C.; Lin, J.; Zhou, Y. Ecological environment quality assessment based on remote sensing data for land consolidation. J. Clean. Prod. 2019, 239, 118126. [CrossRef]

24. Guo, B.; Yelin, F.; Xiaobin, J. Monitoring the effects of land consolidation on the ecological environmental quality based on remote sensing: A case study of Chaohu Lake Basin, China. Land Use Policy 2020, 95, 104569. [CrossRef]

25. Xu, H.; Wang, M.; Shi, T.; Guan, H.; Fang, C.; Lin, Z. Prediction of ecological effects of potential population and impervious surface increases using a remote sensing based ecological index (RSEI). Ecol. Indic. 2018, 93, 730-740. [CrossRef]

26. Liao, W.; Jiang, W. Evaluation of the Spatiotemporal Variations in the EEQ in China Based on the Remote Sensing Ecological Index. Remote Sens. 2020, 12, 2462. [CrossRef]

27. Li, K.; Chen, Y. A Genetic Algorithm-based urban cluster automatic threshold method by combining VIIRS DNB, NDVI, and NDBI to monitor urbanization. Remote Sens. 2018, 10, 277. [CrossRef]

28. Zhang, Q.; Seto, K.C. Mapping urbanization dynamics at regional and global scales using multi-temporal DMSP/OLS nighttime light data. Remote Sens. Environ. 2011, 115, 2320-2329. [CrossRef]

29. Ma, T.; Zhou, Y.; Zhou, C.; Haynie, S.; Pei, T.; Xu, T. Night-time light derived estimation of spatio-temporal characteristics of urbanization dynamics using DMSP/OLS satellite data. Remote Sens. Environ. 2015, 158, 453-464. [CrossRef]

30. Zheng, Z.; Wu, Z.; Chen, Y.; Yang, Z.; Marinello, F. Exploration of eco-environment and urbanization changes in coastal zones: A case study in China over the past 20 years. Ecol. Indic. 2020, 119, 106847. [CrossRef]

31. Chen, J.; Zhuo, L.; Shi, P.J. The study on urbanization process in China based on DMSP/OLS data: Development of a light index for urbanization level estimation. J. Remote Sens. 2003, 7, 168-175.

32. Fang, C.; Wang, S.; Li, G. Changing urban forms and carbon dioxide emissions in China: A case study of 30 provincial capital cities. Appl. Energy 2015, 158, 519-531. [CrossRef]

33. Ozokcu, S.; Özdemir, O. Economic growth, energy, and environmental Kuznets curve. Renew. Sustain. Energy Rev. 2017, 72, 639-647. [CrossRef]

34. Fanning Andrew, L.; O'Neill, D.W.; Büchs, M. Provisioning systems for a good life within planetary boundaries. Glob. Environ. Change 2020, 64, 102135. [CrossRef]

35. O'Neill, D.W.; Fanning, A.L.; Lamb, W.F.; Steinberger, J.K. A good life for all within planetary boundaries. Nat. Sustain. 2018, 1, 88-95. [CrossRef] 
36. Fang, C.; Ren, Y. Analysis of emergy-based metabolic efficiency and environmental pressure on the local coupling and telecoupling between urbanization and the eco-environment in the Beijing-Tianjin-Hebei urban agglomeration. Sci. China Earth Sci. 2017, 60, 1083-1097. [CrossRef]

37. Andrea, L.; Newig, J.; Challies, E. Globalization's limits to the environmental state? Integrating telecoupling into global environmental governance. Environ. Politics 2016, 25, 136-159.

38. Yi, Y.; Meng, G. A bibliometric analysis of comparative research on the evolution of international and Chinese ecological footprint research hotspots and frontiers since 2000. Ecol. Indic. 2019, 102, 650-665.

39. Rashid, A.; Irum, A.; Malik, I.A.; Ashraf, A.; Rongqiong, L.; Liu, G.; Ullah, H.; Ali, M.U.; Yousaf, B. Ecological footprint of Rawalpindi; Pakistan's first footprint analysis from urbanization perspective. J. Clean. Prod. 2018, 170, 362-368. [CrossRef]

40. Beloin-Saint-Pierre, D.; Rugani, B.; Lasvaux, S.; Mailhac, A.; Popovici, E.; Sibiude, G.; Benetto, E.; Schiopu, N. A review of urban metabolism studies to identify key methodological choices for future harmonization and implementation. J. Clean. Prod. 2017, 163, S223-S240. [CrossRef]

41. Wu, Y.; Que, W.; Liu, Y.-G.; Li, J.; Cao, L.; Liu, S.-B.; Zeng, G.-M.; Zhang, J. Efficiency estimation of urban metabolism via Emergy, DEA of time-series. Ecol. Indic. 2018, 85, 276-284. [CrossRef]

42. Yang, S.; Cao, D.; Lo, K. Analyzing and optimizing the impact of economic restructuring on Shanghai's carbon emissions using STIRPAT and NSGA-II. Sustain. Cities Soc. 2018, 40, 44-53. [CrossRef]

43. Song, Q.; Zhou, N.; Liu, T.; Siehr, S.A.; Qi, Y. Investigation of a "coupling model" of coordination between low-carbon development and urbanization in China. Energy Policy 2018, 121, 346-354. [CrossRef]

44. Lowe, R.; Wu, Y.; Tamar, A.; Harb, J.; Abbeel, P.; Mordatch, I. Multi-agent actor-critic for mixed cooperative-competitive environments. Advances in neural information processing systems. arXiv 2017, arXiv:1706.02275.

45. Fang, C.; Liu, H.; Li, G. International progress and evaluation on interactive coupling effects between urbanization and the eco-environment. J. Geogr. Sci. 2016, 26, 1081-1116. [CrossRef]

46. Zhao, Y.; Wang, S.; Zhou, C. Understanding the relation between urbanization and the eco-environment in China's Yangtze River Delta using an improved EKC model and coupling analysis. Sci. Total Environ. 2016, 571, 862-875. [CrossRef] [PubMed]

47. Li, Y.; Li, Y.; Zhou, Y.; Shi, Y.; Zhu, X. Investigation of a coupling model of coordination between urbanization and the environment. J. Environ. Manag. 2012, 98, 127-133. [CrossRef] [PubMed]

48. Wang, S.J.; Ma, H.; Zhao, Y.B. Exploring the relationship between urbanization and the eco-environment-A case study of Beijing-Tianjin-Hebei region. Ecol. Indic. 2014, 45, 171-183. [CrossRef]

49. Li, W.; Yi, P. Assessment of city sustainability-Coupling coordinated development among economy, society and environment. J. Clean. Prod. 2020, 256, 120453. [CrossRef]

50. Qu, B.; Zhang, Y.; Kang, S.; Sillanpää, M. Water quality in the Tibetan Plateau: Major ions and trace elements in rivers of the "Water Tower of Asia". Sci. Total Environ. 2019, 649, 571-581. [CrossRef]

51. Fan, Y.; Fang, C.; Zhang, Q. Coupling coordinated development between social economy and ecological environment in Chinese provincial capital cities-assessment and policy implications. J. Clean. Prod. 2019, 229, 289-298. [CrossRef]

52. Peng, S.; Ding, Y.; Liu, W.; Li, Z. 1 km monthly temperature and precipitation dataset for China from 1901 to 2017. Earth Syst. Sci. Data 2019, 11, 1931-1946. [CrossRef]

53. Wang, S.; Hu, D.; Yu, C.; Chen, S.; Di, Y. Mapping China's time-series anthropogenic heat flux with inventory method and multi-source remotely sensed data. Sci. Total Environ. 2020, 734, 139457. [CrossRef]

54. Zhao, G.; Chen, L.; Mu, J. Discussion on Construction of Ecological Environment Quality Evaluation System. Meteorol. Environ. Sci. 2018, 2018, 1-11.

55. Lu, Y.; Xiang, P. Analysis of the Coupling Relationship between Ecological Environment and Urbanization:Chang-Zhu-Tan Urban Agglomeration in Hunan Province, China as a Case. Urban Dev. Res. 2020, 1, 19.

56. Cao, Z.; Wu, Z.; Kuang, Y.; Huang, N. Correction of DMSP/OLS Night-time Light Images and Its Application in China. J. Earth Inf. Sci. 2015, 17, 1092-1102.

57. Cao, Z.; Wu, Z.; Mi, S.; Yang, K. A Method for Classified Correction of Stable DMSP/OLS night-time Light Imagery across China. J. Earth Inf. Sci. 2020, 22, 246-257.

58. Liao, L.; Dai, W.; Huang, F.H.; Hu, Q. Coupling Coordination Analysis of Urbanization and Eco-environment System in Jinjiang Using Landsat Series Data and DMSP/OLS Nighttime Light Data. J. Fujian Norm. Univ. Nat. Sci. Ed. 2018, 6, 16.

59. Yajie, Z.; Huizhi, L. Spatial-Temporal Coupled Coordination between Urbanization and Ecological Environment in Yangtze River Economic Belt. Bull. Soil Water Conserv. 2018, 37, 334-340.

60. Li, S.; Yan, J.; Wan, J. The Spatial-temporal Changes of Vegetation Restoration on Loess Plateau in Shaanxi-Gansu-Ningxia Region. Acta Geogr. Sin. 2012, 67, 960-970.

61. Chen, J.; Jia, W.; Zhao, Z.; Zhang, Y.; Liu, Y. Research on Temporal and Spatial Variation Characteristics of Vegetation Cover of Qilian Mountains from 1982 to 2006. Adv. Earth Sci. 2015, 30, 834-845.

62. Fensholt, R.; Proud, S.R. Evaluation of earth observation based global long term vegetation trends-Comparing GIMMS and MODIS global NDVI time series. Remote Sens. Environ. 2012, 119, 131-147. [CrossRef]

63. Yuan, S.; Huichun, S.; Minhui, X.; Pengxia, Z. Spatiotemporal evolution pattern and influencing factors of EEQ in Gansu from 2000 to 2017. J. Ecol. 2019, 38, 3800-3808. 
64. Zhou, Z.; Wang, X.; Ding, Z.; Chen, Y.; Wang, C. Remote sensing analysis of ecological quality change in Xinjiang. J. Ecol. 2020, 40, 2907-2919.

65. Xu, D.; Yang, F.; Yu, L.; Zhou, Y.; Li, H.; Ma, J.; Huang, J.; Wei, J.; Xu, Y.; Zhang, C.; et al. Quantization of the coupling mechanism between eco-environmental quality and urbanization from multisource remote sensing data. J. Clean. Prod. 2021, $321,128948$. [CrossRef]

66. Dewan, A.M.; Yamaguchi, Y. Land use and land cover change in Greater Dhaka, Bangladesh: Using remote sensing to promote sustainable urbanization. Appl. Geogr. 2009, 29, 390-401. [CrossRef]

67. Taubenböck, H.; Wegmann, M.; Roth, A.; Mehl, H.; Dech, S. Urbanization in India-Spatiotemporal analysis using remote sensing data [J]. Comput. Environ. Urban Syst. 2009, 33, 179-188. [CrossRef]

68. Xu, Y.; Yu, L.; Peng, D.; Zhao, J.; Cheng, Y.; Liu, X.; Li, W.; Meng, R.; Xu, X.; Gong, P. Annual 30-m land use/land cover maps of China for 1980-2015 from the integration of AVHRR, MODIS and Landsat data using the BFAST algorithm. Sci. China Earth Sci. 2020, 63, 1390-1407. [CrossRef]

69. Kyba, C.; Kuester, T.; de Miguel, A.S.; Baugh, K.; Jechow, A.; Hölker, F.; Bennie, J.; Elvidge, C.; Gaston, K.; Guanter, L. Artificially lit surface of Earth at night increasing in radiance and extent. Sci. Adv. 2017, 3, e1701528. [CrossRef] 